The University of Maine

DigitalCommons@UMaine

Marine Sciences Faculty Scholarship

School of Marine Sciences

$10-1-2004$

\title{
Modeling the spectral shape of absorption by chromophoric dissolved organic matter
}

\author{
Michael S. Twardowski \\ W. Environ. Technology Laboratories, Inc. \\ Emmanuel Boss \\ University of Maine, emmanuel.boss@maine.edu \\ James M. Sullivan \\ University of Rhode Island Narragansett Bay Campus \\ Percy L. Donaghay \\ University of Rhode Island Narragansett Bay Campus
}

Follow this and additional works at: https://digitalcommons.library.umaine.edu/sms_facpub

\section{Repository Citation}

Twardowski, Michael S.; Boss, Emmanuel; Sullivan, James M.; and Donaghay, Percy L., "Modeling the spectral shape of absorption by chromophoric dissolved organic matter" (2004). Marine Sciences Faculty Scholarship. 157.

https://digitalcommons.library.umaine.edu/sms_facpub/157

This Conference Proceeding is brought to you for free and open access by DigitalCommons@UMaine. It has been accepted for inclusion in Marine Sciences Faculty Scholarship by an authorized administrator of DigitalCommons@UMaine. For more information, please contact um.library.technical.services@maine.edu. 


\title{
Modeling the spectral shape of absorption by chromophoric dissolved organic matter
}

\author{
Michael S. Twardowski ${ }^{\mathrm{a}, *}$, Emmanuel Boss ${ }^{\mathrm{b}}$, James M. Sullivan ${ }^{\mathrm{c}}$, Percy L. Donaghay $^{\mathrm{c}}$ \\ ${ }^{a}$ Department of Research, Western Environmental Technology Laboratories, Inc., 165 Dean Knauss Dr., Narragansett, RI 02882, USA \\ ${ }^{\mathrm{b}}$ School of Marine Sciences, University of Maine, Orono, ME 04469, USA \\ ${ }^{\mathrm{c}}$ Graduate School of Oceanography, University of Rhode Island, Narragansett, RI 02882, USA
}

Received 21 January 2003; accepted 9 February 2004

Available online 28 May 2004

\begin{abstract}
A single exponential model of the form $a_{g}(\lambda) \propto \mathrm{e}^{-s_{e} \lambda}$ was evaluated in the context of its application and interpretation in describing absorption by chromophoric dissolved organic matter (CDOM), $a_{g}$, as a function of wavelength, $\lambda$. The spectral slope, $s_{e}$, is often used as a proxy for CDOM composition, including the ratio of fulvic to humic acids and molecular weight. About three-quarters of the variability in $s_{e}$ values from the literature could be explained by the different spectral ranges used in each study. Dependency on different spectral ranges resulted from the relatively weak performance of the single exponential as a descriptor of $a_{g}(\lambda)$ in comparison to other models that allow for greater spectral curvature. Consequently, actual variability in the spectral shape of absorption, and thus the composition of CDOM, from widely varying water types appears less than currently thought.

The usefulness of five other models in describing CDOM absorption spectra in the visible domain was also evaluated. Six data sets collected with an ac9 in-situ spectrophotometer from around the coastal United States were used in the analysis. All models considered performed better than the conventional single exponential model, with the exception of a double exponential model, where the second exponential term contributed little new information in the fit. Statistically, the most "useful" model (judged by an analysis of variance) in the visible range was a hyperbolic model of the form: $a_{g}(\lambda) \propto \lambda^{-s_{h}}$. Although the hyperbolic model was less dependent on the spectral range used in the fit, some dependency remained. The most representative model for describing $a_{g}(\lambda)$ from the six regions considered in this study, with $a_{g}$ at $412 \mathrm{~nm}$ as input, was: $a_{g}(\lambda)=a_{g}(412)(\lambda /$ $412)^{-6.92}$. This spectral relationship may be suitable for remote sensing semi-analytical models which must compute a spectrum from a single estimate of CDOM absorption in the blue derived from a remotely sensed water-leaving radiance signal.

(C) 2004 Elsevier B.V. All rights reserved.
\end{abstract}

Keywords: Chromophoric dissolved organic matter (CDOM); Absorption; Spectrum

\section{Introduction}

Chromophoric dissolved organic matter (CDOM;

* Corresponding author. Tel.: +1-401-783-1787; fax: +1-401783-0309.

E-mail address: mtwardo@wetlabs2.com (M.S. Twardowski). also Gelbstoff or yellow substances) is the pool of absorbing substances in water that passes a filter typically of $0.2 \mu \mathrm{m}$ pore size (Blough and Del 
Vecchio, 2002). CDOM comprises a significant fraction of the DOM pool in natural waters $(\sim 10-90 \%$, Thurman, 1985) and influences upper water column photoprocesses (Miller, 1998), nutrient availability (Bushaw et al., 1996), availability of light for primary production (Wrigley et al., 1988; Davies-Colley, 1992), and water-leaving radiance (e.g., Carder et al., 1991, 1999). A rigorous understanding of the spectral character of absorption by CDOM is necessary to accurately model the role of CDOM in many of these processes. For example, in remote sensing semi-analytical models the absorption by CDOM must be extrapolated from the blue region to the rest of the visible to derive other in-water properties such as phytoplankton absorption from spectra of total absorption or water-leaving radiance (Carder et al., 1991, 1999; Roesler and Perry, 1995; Ciotti et al., 1999). An understanding of this spectral character can also be used to assess the "nature" and variability in composition of the CDOM pool (Blough and Green, 1995). For example, the spectral shape can identify alterations to CDOM that occur from processes such as photobleaching (Vodacek et al., 1997; Twardowski and Donaghay, 2002).

Absorption by CDOM as a function of wavelength, $a_{g}(\lambda)\left(\mathrm{m}^{-1}\right)$, is commonly modeled with an exponentially decreasing function (Jerlov, 1976; Shifrin, 1988) of the form:

$a_{g}(\lambda)=a_{g}\left(\lambda_{\mathrm{r}}\right) \mathrm{e}^{-s_{e}\left(\lambda-\lambda_{\mathrm{r}}\right)}$,

or more generally,

$a_{g}(\lambda)=A \mathrm{e}^{-S_{e} \lambda}$,

where $\lambda_{\mathrm{r}}$ is a reference wavelength, $A$ is amplitude and $s_{e}\left(\mathrm{~nm}^{-1}\right)$ is the spectral slope parameter describing the relative steepness of the spectrum. The amplitude is a proxy for concentration, and the $s_{e}$ parameter is often used as a proxy for changes in the composition of $\mathrm{CDOM}$, including the ratio of humic acids to fulvic acids (e.g., Carder et al., 1989; Blough and Green, 1995).

In general, published spectral slope values are contradictory. Although many authors find remarkably little variability in the slope parameter in their specific data sets, when the slope values of different investigators are compared, there are often large differences (Table 1). The question then arises, how much of the observed discrepancies in previous works are the result of methodological differences, i.e., the chosen spectral model and fitting method, and how much is potentially real variability in the composition of CDOM? The question has practical significance when an "average" $s_{e}$ value must be chosen for remote sensing bio-optical models which incorporate the single exponential model (e.g., Carder et al., 1999). Should a value of $0.023 \mathrm{~nm}^{-1}$ be used as may be inferred from the recent work of Højerslev and Aas (2001) based on analyses of over 1000 samples in the Baltic, or should a more "typical" value (e.g., Bricaud et al., 1981; Zepp and Schlotzhauer, 1981) of 0.014 or $0.015 \mathrm{~nm}^{-1}$ be used instead?

Spectral slope values around 0.014 to 0.015 $\mathrm{nm}^{-1}$ are considered "typical" from historical precedence. Bricaud et al. (1981) found slope values varied over a relatively small range of $0.0140 \pm$ $0.0032 \mathrm{~nm}^{-1}$ and observed a lack of pattern between $s_{e}$ and source water samples from a variety of source regions. Similarly, Zepp and Schlotzhauer (1981) found a "striking similarity" in spectral slopes from different marine waters. The mean and standard deviation they observed were $0.0140 \pm 0.001 \mathrm{~nm}^{-1}$. Davies-Colley (1992) found an average of 0.015 $\mathrm{nm}^{-1}$ with a standard deviation of 0.002 for waters around coastal New Zealand. Recent absorption measurements in the visible region $(412-560 \mathrm{~nm})$ using an ac9 in-situ spectrophotometer (WET Labs) deployed in a fjord and fitted with a $0.2 \mu \mathrm{m}$ prefilter, also exhibited spectral slopes that varied only from about 0.013 to $0.016 \mathrm{~nm}^{-1}$ with the majority of the samples falling in the range $0.014 \pm 0.001 \mathrm{~nm}^{-1}$ (Twardowski and Donaghay, 2002). Both Jerlov's "Optical Oceanography" (1976) and Shifrin's "Physical Optics of Ocean Water" (1988) recommend a value of $0.015 \mathrm{~nm}^{-1}$.

Other recent works (e.g., Green and Blough, 1994; Vodacek et al., 1997; Nelson et al., 1998; Del Castillo et al., 1999; Kowalczuk, 1999; Højerslev and Aas, 2001; Schwarz et al., 2002) have observed spectral slope values higher than found previously (typically greater than about $0.018 \mathrm{~nm}^{-1}$; Table 1), with generally a greater range of variability. Reconciling these observations with lower values found in other works is important in helping to promote a greater understanding of the true variability in the spectral shape of 
Table 1

Spectral slope values for marine samples reported in the literature with spectral range, CDOM absorption at $412 \mathrm{~nm}$, and reported precision (ordered according to starting wavelength range)

\begin{tabular}{|c|c|c|c|c|c|c|}
\hline Reference & Location & $n^{\mathrm{a}}$ & Slope $\left(\mathrm{nm}^{-1}\right)^{\mathrm{b}}$ & $\begin{array}{l}\text { Wavelength } \\
\text { range }\end{array}$ & $a_{\mathrm{g}}(412)\left(\mathrm{m}^{-1}\right)^{\mathrm{c}}$ & $\operatorname{Prec}\left(\mathrm{m}^{-1}\right)$ \\
\hline $\begin{array}{l}\text { Højerslev and Aas } \\
\text { (2001) }\end{array}$ & Kattegat-Skagerrak & 1305 & $\begin{array}{l}0.0234 \pm 0.0036 \\
{[0.0075-0.0420]}\end{array}$ & {$[250-450]$} & $1.28 \pm 0.70$ & 0.002 \\
\hline \multirow[t]{3}{*}{ Brown (1977) } & North Sea & 37 & {$[0.0187-0.0306]$} & 280,310 & {$[0.022-0.327]$} & $?$ \\
\hline & Baltic proper & 157 & {$[0.0247-0.0305]$} & 280,310 & {$[0.136-0.284]$} & $?$ \\
\hline & Baltic riverine & 1 & 0.0173 & 280,310 & 2.49 & $?$ \\
\hline Nelson et al. (1998) & Bermuda & $?$ & 0.0235 & $280-350$ & $\sim 0.1-0.4$ & 0.03 \\
\hline Blough et al. (1993) & $\begin{array}{l}\text { Gulf of Paria } \\
\text { (samples }<30 \mathrm{ppt} \text { ) }\end{array}$ & 47 & $0.0140 \pm 0.0003$ & {$[290-600+]^{\mathrm{d}}$} & {$[1.25-4.59]$} & 0.092 \\
\hline \multirow[t]{2}{*}{$\begin{array}{l}\text { Green and Blough } \\
\text { (1994) }\end{array}$} & $\begin{array}{l}\text { S. Florida/Gulf of } \\
\text { Mexico }\end{array}$ & 31 & $\begin{array}{l}0.021 \pm 0.005 \\
{[0.015-0.034]}\end{array}$ & {$[290-(330-675)]^{\mathrm{d}}$} & {$[0.01-6.32]$} & 0.092 \\
\hline & Amazon R. estuary & 12 & $\begin{array}{l}0.019 \pm 0.005 \\
{[0.014-0.033]}\end{array}$ & {$[290-(370-590)]^{\mathrm{d}}$} & {$[0.03-1.33]$} & 0.092 \\
\hline \multirow[t]{4}{*}{ Vodacek et al. (1997) } & coastal Mid-Atlantic & & & & & \\
\hline & Bight: non-Nov. & $\sim 40$ & 0.018 average & {$[290-(440-550)]^{\mathrm{d}}$} & {$[0.14-0.71]$} & 0.092 \\
\hline & Nov. & $\sim 25$ & 0.014 average & {$[290-(400-550)]^{\mathrm{d}}$} & {$[0.14-0.63]$} & 0.092 \\
\hline & $\begin{array}{l}\text { offshore Mid-Atlantic } \\
\text { Bight }\end{array}$ & $\sim 150$ & {$[0.010-0.034]$} & {$[290-(340-440)]^{\mathrm{d}}$} & {$[0.009-0.14]$} & 0.092 \\
\hline \multirow{2}{*}{$\begin{array}{l}\text { Del Castillo et al. } \\
\text { (1999) }\end{array}$} & Gulf of Paria and & 8 & $0.018 \pm 0.002$ & {$[290-\mathrm{var}]^{\mathrm{e}}$} & {$[0.09-1.34]$} & 0.046 \\
\hline & surrounding waters & 8 & $0.017 \pm 0.002$ & {$[290-\mathrm{var}]^{\mathrm{d}}$} & {$[0.09-1.34]$} & 0.046 \\
\hline \multirow[t]{2}{*}{$\begin{array}{l}\text { Zepp and Schlotzhauer } \\
\text { (1981) }\end{array}$} & $\begin{array}{l}\text { Gulf of Mexico, } \\
\text { St. Marks, FL }\end{array}$ & 1 & 0.0151 & {$[300-500]$} & $?$ & $?$ \\
\hline & 'Marine aquatic humus' & 3 & 0.0147 & {$[300-500]$} & $?$ & $?$ \\
\hline \multirow[t]{2}{*}{ Davies-Colley (1992) } & coastal N. Zealand & 28 & $0.015 \pm 0.002$ & {$[300-460]$} & {$[0.023-0.165]$} & 0.017 \\
\hline & Doubtful Sound & 6 & $0.014 \pm 0.0004$ & {$[300-460]$} & {$[0.678-2.60]$} & 0.017 \\
\hline Stedmon et al. (2000) & $\begin{array}{l}\text { Danish fjords and } \\
\text { nearby coastal waters }\end{array}$ & 586 & $0.0194 \pm 0.0032^{\mathrm{f}}$ & {$[300-650]$} & {$[0.14-3.46]$} & $?$ \\
\hline \multirow{3}{*}{$\begin{array}{l}\text { Stedmon and Markager } \\
\text { (2001) }\end{array}$} & Greenland Sea, Nov 98 & 20 & $0.02016 \pm 0.00252$ & {$[300-650]$} & {$[0.04-0.08]$} & 0.05 \\
\hline & Greenland Sea, Jun 99 & 107 & $0.01651 \pm 0.00352$ & {$[300-650]$} & {$[0.04-0.70]$} & 0.05 \\
\hline & Greenland Sea, Aug 99 & 67 & $0.01622 \pm 0.00297$ & {$[300-650]$} & {$[0.04-0.31]$} & 0.05 \\
\hline \multirow[t]{6}{*}{ Bricaud et al. (1981) } & Mauritanian upwelling & 24 & $0.015 \pm 0.0023$ & $350: 10: 500^{\mathrm{g}}$ & {$[0.03-0.12]$} & 0.01 \\
\hline & Gulf of Guinea & 35 & $0.014 \pm 0.0041$ & $350: 25: 500^{\mathrm{g}}$ & {$[0.04-0.17]$} & 0.01 \\
\hline & Villefrance Bay & 11 & $0.014 \pm 0.0024$ & $350: 25: 500^{\mathrm{g}}$ & {$[0.09-0.24]$} & 0.01 \\
\hline & Var River & 1 & 0.015 & $350: 25: 500^{\mathrm{g}}$ & 0.21 & 0.01 \\
\hline & Baltic Sea & 1 & 0.018 & $350: 25: 500^{\mathrm{g}}$ & 2.18 & 0.01 \\
\hline & Gulf of Fos-sur-Mer & 14 & $0.013 \pm 0.0012$ & $350: 25: 500^{\mathrm{g}}$ & {$[0.12-0.82]$} & 0.01 \\
\hline \multirow{4}{*}{$\begin{array}{l}\text { Kowalczuk et al. } \\
\text { (in press) }\end{array}$} & Baltic, open sea & 754 & $0.019 \pm 0.004$ & {$[350-$ var $]$} & {$[0.18-1.46]$} & $0.023 / 0.046$ \\
\hline & Baltic, coastal & 221 & $0.020 \pm 0.003$ & {$[350-$ var $]$} & {$[0.20-1.88]$} & $0.023 / 0.046$ \\
\hline & Pomeranian Bight & 312 & $0.020 \pm 0.004$ & {$[350-$ var $]$} & {$[0.21-1.71]$} & $0.023 / 0.046$ \\
\hline & Bay of Gdansk & 1292 & $0.019 \pm 0.004$ & {$[350-$ var $]$} & {$[0.20-3.52]$} & $0.023 / 0.046$ \\
\hline Schwarz et al. (2002) & Globally representative & 877 & $0.01725 \pm 0.0034$ & {$[350-$ var $]$} & {$[\sim 0.003-10.0]$} & $0.046^{\mathrm{h}}$ \\
\hline Carder et al. (1989) & Gulf of Mexico & 11 & {$[0.0115-0.0172]$} & {$[370-440]$} & {$[0.002-0.074]$} & $\sim 0.01$ \\
\hline $\begin{array}{l}\text { Kopelevich and } \\
\text { Burenkov (1977) }\end{array}$ & Deep Indian and Pacific & 2 & 0.017 & $390: 20: 490^{\mathrm{g}}$ & $\sim 0.06$ & $?$ \\
\hline Roesler et al. (1989) & San Juan Islands & 21 & $0.017 \pm 0.003$ & [400-750?] & 0.32 average & ? \\
\hline $\begin{array}{l}\text { Del Castillo et al. } \\
\text { (1999) }\end{array}$ & $\begin{array}{l}\text { Gulf of Paria and } \\
\text { surrounding waters }\end{array}$ & 8 & $0.015 \pm 0.001$ & {$[400-500]$} & {$[0.09-1.34]$} & 0.046 \\
\hline Maske et al. (1998) & Gulf of California & $?$ & 0.014 & $412,440,512$ & $\sim 0.095$ & 0.002 \\
\hline
\end{tabular}


Table 1 (continued)

\begin{tabular}{|c|c|c|c|c|c|c|}
\hline Reference & Location & $n^{\mathrm{a}}$ & Slope $\left(\mathrm{nm}^{-1}\right)^{\mathrm{b}}$ & $\begin{array}{l}\text { Wavelength } \\
\text { range }\end{array}$ & $a_{\mathrm{g}}(412)\left(\mathrm{m}^{-1}\right)^{\mathrm{c}}$ & $\operatorname{Prec}\left(\mathrm{m}^{-1}\right)$ \\
\hline \multirow[t]{4}{*}{ Kalle (1966) } & Baltic proper & 1 & 0.0115 & 420,665 & 0.783 & $?$ \\
\hline & North Sea & 1 & 0.0109 & 420,665 & 0.251 & $?$ \\
\hline & N. Atlantic & 1 & 0.0107 & 420,665 & 0.038 & $?$ \\
\hline & Lower Elbe R. & 1 & 0.0097 & 420,665 & 3.73 & $?$ \\
\hline Carder et al. (1989) & Gulf of Mexico & 11 & {$[0.0110-0.0161]$} & {$[440-565]$} & {$[0.002-0.074]$} & $\sim 0.01$ \\
\hline Davies-Colley (1992) & Doubtful Sound & 6 & $0.0091 \pm 0.0006$ & $460-600$ & {$[0.678-2.60]$} & 0.017 \\
\hline Maske et al. (1998) & Gulf of California & $?$ & 0.007 & $512,550,630,675$ & $\sim 0.095$ & 0.002 \\
\hline $\begin{array}{l}{ }^{\mathrm{a}} \text { Number of sampl } \\
\mathrm{b} \pm \text { denotes standa } \\
{ }^{\mathrm{c}} \text { If absorption at } 4 \\
{ }^{\mathrm{d}} \text { Long wavelength } \\
{ }^{\mathrm{e}} \text { Long wavelength } \\
{ }^{\mathrm{f}} \text { Nonlinear method } \\
{ }_{\mathrm{g}}^{\mathrm{g}} \text { Formatted as (star } \\
{ }^{\mathrm{h}} \text { Pers. comm. with }\end{array}$ & $\begin{array}{l}\text { deviation, and brack } \\
\text { nm was not reported } \\
\mathrm{d} \text { member is variabl } \\
\mathrm{d} \text { member is variable } \\
\text { heir method } 2 \text {, referr } \\
\text { f range):(increment) } \\
\text { Kowalczuk. }\end{array}$ & $\begin{array}{l}\text { hote } \\
\text { s calc } \\
\text { led } w \\
\text { ed } w \\
\text { in as } \\
\text { f ran }\end{array}$ & $\begin{array}{l}\text { ange reported. } \\
\text { d from the } a_{g}(\lambda) \text { an } \\
l_{g} \text { drops below prec } \\
l_{g} \text { drops below } 0.09 \\
\text { SEM). }\end{array}$ & $\begin{array}{l}\text { he slope value. } \\
\text { on. } \\
n^{-1} \text {. }\end{array}$ & & \\
\hline
\end{tabular}

CDOM absorption and, consequently, the variability in the composition of the CDOM pool.

Notable progress has been made toward this end in several recent studies. First, it has been established that different spectral slopes are obtained when different portions of CDOM absorption spectra are modeled (Del Castillo et al., 1999; Gege, 2000; Sipelgas et al., 2000; Stedmon et al., 2000; Schwarz et al., 2002). Second, it has been observed that applying the exponential model as a linear fit to logarithmically transformed absorption spectra does not result in the same spectral slope values as applying a nonlinear exponential model (Stedmon et al., 2000; Blough and Del Vecchio, 2002). Thus, spectral range and fitting method are clearly factors that should be considered in reconciling the various published slope data and in working toward a common methodology for modeling CDOM absorption spectra.

Our objectives here are to evaluate the implications of using the exponential model to approximate CDOM absorption spectra in terms of understanding actual natural variability in CDOM pools, and to determine if another model may be more applicable. The method of applying Eq. (1) or (2) to absorption spectra is examined. Spectral slopes are calculated over different spectral ranges for a single CDOM absorption spectrum and the results are compared to reported $s_{e}$ values in an effort to estimate how much of the variability in the literature is the result of an inexact model, and how much is real variability in CDOM composition. The performance of the single exponential model and five other fitting models is also evaluated with a diverse data set of visible absorption spectra in an effort to determine which model is most useful, at least in a statistical sense, in describing natural $a_{g}(\lambda)$.

\section{Methods}

\subsection{Absorption measurements}

CDOM absorption spectra were measured two ways: in-situ with a WET Labs ac9, and in-vitro with a bench top Cary-118 spectrophotometer.

The ac9 is a nine wavelength $(412,440,488,532$, 555 or $560,630,650,676$, and $715 \mathrm{~nm}$ ), in-situ absorption $(a)$ and attenuation $(c)$ meter with a pathlength of $25 \mathrm{~cm}$. For in-situ measurements, a SeaBird Electronics submersible pump was used to pull the sample through a "Y" fitting into the respective absorption and attenuation channel flow cells. Particulate material was removed with a large area $0.2 \mu \mathrm{m}$ maxi-capsule filter (Gelman) attached to the intake of the "Y" (Twardowski et al., 1999). Flow rates were about $1.0 \pm 0.21 \mathrm{~min}^{-1}$, as determined with an in-line flow meter. The ac9 was one component of an integrated finescale profiler (Donaghay et al., 1992). Calibrations with purified water (Barnstead 4-cartridge "organic-free" Nanopure system) were carried out in the field to correct for ac9 instrument drifts and remove pure water absorption and attenuation from 
measured spectra (a blank equivalent) (Twardowski et al., 1999). Additional corrections were made to account for flow time lags, the temperature dependence of the absorption by pure water, and absorption and refractive index effects related to dissolved salts as described by Pegau et al. (1997) and Twardowski et al. (1999). The same ac9 was used for all measurements presented here.

Scattering by particles less than $0.2 \mu \mathrm{m}$ has been recognized as a potential source of error in making absorption measurements in the dissolved fraction of seawater (e.g., Aas, 2000). The absorption tube of the ac9 is reflective with a diffuser at the end, designed to minimize such scattering errors. Small scattering errors may nonetheless remain, and there are a variety of methods for correction (Zaneveld et al., 1994). No such correction was made here for two primary reasons (more detailed justification in Twardowski and Donaghay, 2001). First, all the measurements of the dissolved fraction were made in both the attenuation $\left(c_{g}\right)$ and absorption $\left(a_{g}\right)$ channels of the ac9, and both $c_{g}$ and $a_{g}$ always agreed within the precision of the measurement (about $0.002 \mathrm{~m}^{-1}$ ). Since attenuation is comprised of the sum of total absorption and total scattering, any scattering error in the absorption channel would be observed as a larger error in the attenuation channel and $c_{g}>a_{g}$ would be expected. Second, both $a_{g}(650)$ and $a_{g}(715)$ are highly correlat- ed with $a_{g}(412)$. Since absorption by CDOM is very low at the longer wavelengths, any scattering error present is expected to dominate these signals. The high correlation with $a_{g}$ at $412 \mathrm{~nm}$, a spectral region with much higher CDOM absorption, is evidence of a common source for all the signals, CDOM absorption.

The sites where the ac9 was deployed to measure CDOM absorption are mapped in Fig. 1 and listed in Table 2 with brief descriptions.

The Cary-118 was used for high spectral resolution absorption measurements in the ultraviolet and visible domains, in a dual beam configuration. Blank and sample were measured at room temperature in matched $10-\mathrm{cm}$ quartz cuvettes. Samples were filtered through $0.2 \mu \mathrm{m}$ polycarbonate Nuclepore filters. Water samples were also run through an ac9 to verify any scattering errors in the spectra from the Cary instruments were negligible. Spectra were recorded either as percent transmission, $T$, or absorbance, $A$. Absorption coefficients, $a$, were obtained from $a=-\ln (T / 100) / \ell$, and $a=2.303 \mathrm{~A} / \ell$, where $\ell$ was the pathlength $(0.1 \mathrm{~m})$.

\subsection{Analysis of bias errors to constrain application of models}

Unbiased, normally distributed errors for ac9 absorption measurements typically have a standard deviation of $0.001 \mathrm{~m}^{-1}$ or less. There is, however,

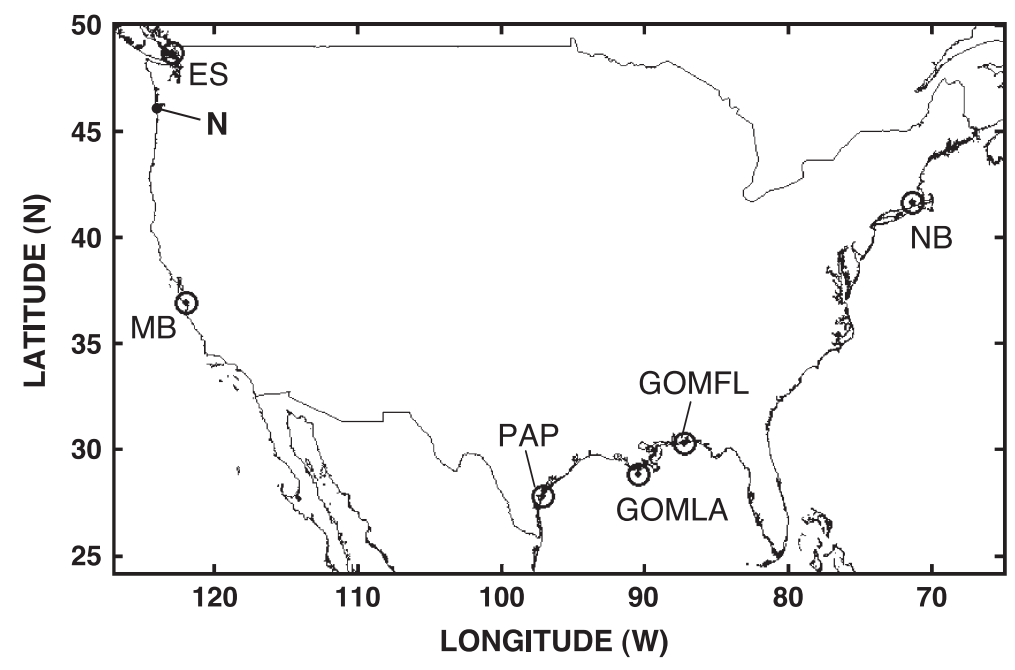

Fig. 1. Map of the coastal United States with each of the six study sites marked with a bull's-eye. Site labels correspond with Table 2. The point of collection for the Newport seawater is marked " $\mathrm{N}$ ". 
Table 2

Study sites information

\begin{tabular}{|c|c|c|c|c|c|}
\hline Site & Label & Dates sampled & $\begin{array}{l}\text { Number of } \\
\text { spectra }^{\mathrm{a}}\end{array}$ & Brief description & Primary river source \\
\hline East Sound, WA & ES & $\begin{array}{l}\text { June } 12 \text { through } \\
\text { June } 24,1998\end{array}$ & 852 & High productivity, stratified fjord & Fraser \\
\hline Monterey Bay, CA & $\mathrm{MB}$ & August 13, 2002 & 129 & High productivity, coastal shelf & Salinas \\
\hline Port Aransas Pass, TX & PAP & July 16, 2002 & 48 & $\begin{array}{l}\text { Moderate productivity, well-mixed } \\
\text { estuary }\end{array}$ & Guadalupe \\
\hline $\begin{array}{l}\text { Gulf of Mexico, } \\
\text { LA coast off Cocodrie }\end{array}$ & GOMLA & $\begin{array}{l}\text { April, } 27 \text { through } \\
\text { May } 3,2002\end{array}$ & 266 & Low productivity, coastal shelf & Mississippi \\
\hline $\begin{array}{l}\text { Gulf of Mexico, } \\
\text { FL coast off Pensacola }\end{array}$ & GOMFL & September 20, 2001 & 9 & Low productivity, coastal shelf & $\begin{array}{l}\text { Escambia/ } \\
\text { Blackwater }\end{array}$ \\
\hline Narragansett Bay, RI & NB & April 26, 2001 & 135 & $\begin{array}{l}\text { High productivity, well-mixed } \\
\text { estuary }\end{array}$ & $\begin{array}{l}\text { Blackstone/ } \\
\text { Pawtuxet }\end{array}$ \\
\hline
\end{tabular}

${ }^{\mathrm{a}} 1 \mathrm{~m}$ binned, typically $\sim 60$ spectra/bin.

uncertainty in the absolute value in absorption resulting primarily from how well the ac9 can be calibrated with a clean water standard (Twardowski et al., 1999). For ac9s manufactured or refitted after 1998, the maximum associated bias error is estimated at 0.002 $\mathrm{m}^{-1}$, based on (1) the reproducibility of data from consecutive calibrations, and (2) the agreement in absorption estimates between multiple ac9s in the field.

The bootstrap method (Efron and Tibshirani, 1986) was used to estimate errors in our model fits and to determine which wavelengths in the red portion of the spectrum could be included while maintaining satisfactory accuracy (Fig. 2) ( $a_{g}$ at $715 \mathrm{~nm}$ was a priori not used because absorption by water at this wavelength is strongly dependent on temperature; Pegau et al., 1997). In the bootstrap analysis, random bias errors between $\pm 0.002 \mathrm{~m}^{-1}$ were added at all wavelengths to 1000 identical $a_{g}$ spectra. The amplitude (from Eq. (2)) of the original spectrum was then sequentially increased to simulate increased CDOM concentrations and the analysis was repeated. A single exponential model was used in the analysis because it is currently the conventional model (see next section for details of fitting algorithm). Once the random errors were added, Eq. (2) was fit by the least-squares method to each spectrum, and the percent error was determined between the exponential slope computed with the added error and original slope before the error was added (Fig. 2). Results indicate that slope estimates within $\pm 5 \%$ of their true value can be obtained with $95 \%$ confidence for $a_{g}(650)$ values of about $0.003 \mathrm{~m}^{-1}$. Higher $a_{g}(650)$ values improve this percent error. This was adapted as an appropriate cutoff in $a_{g}(650)$ for all the data in the analyses of the performance of various fitting models in Section 3.3. Thus, all ac 9 data considered fall in the 412 to $650 \mathrm{~nm}$ spectral range (7 points) and have $a_{g}$ values $0.003 \mathrm{~m}^{-1}$ or higher. Values at $a_{g}(676)$ were not included because many of the very low absorbing samples representative of more oceanic type waters would have to have been excluded.

The spectral interference filters used in the ac 9 to obtain the signal at each of the nine wavelengths have approximately Gaussian-shaped weighting functions with widths of $10 \mathrm{~nm}$ at half the maximum modal value. Stated another way, the weighting functions are Gaussian with a standard deviation of $4.25 \mathrm{~nm}$ around the mode. The effect of this weighting in reproducing CDOM absorption at the central wavelength for each ac9 channel was examined. High resolution CDOM absorption spectra from bench top measurements and spectra fabricated using the single exponential model were convolved with this Gaussian weighting for each interference filter to derive equivalent ac9 values. For spectra matching the highest $a_{g}$ values observed in any of the data presented herein, the largest deviation between an original value at a central wavelength and the ac9 derived value was about $0.002 \mathrm{~m}^{-1}$, or about the estimated precision of the absorption measurements with the ac9. As a result of such sensitivity analyses, the effect was determined to be negligible. It is also important to note that although the small differences between the original 


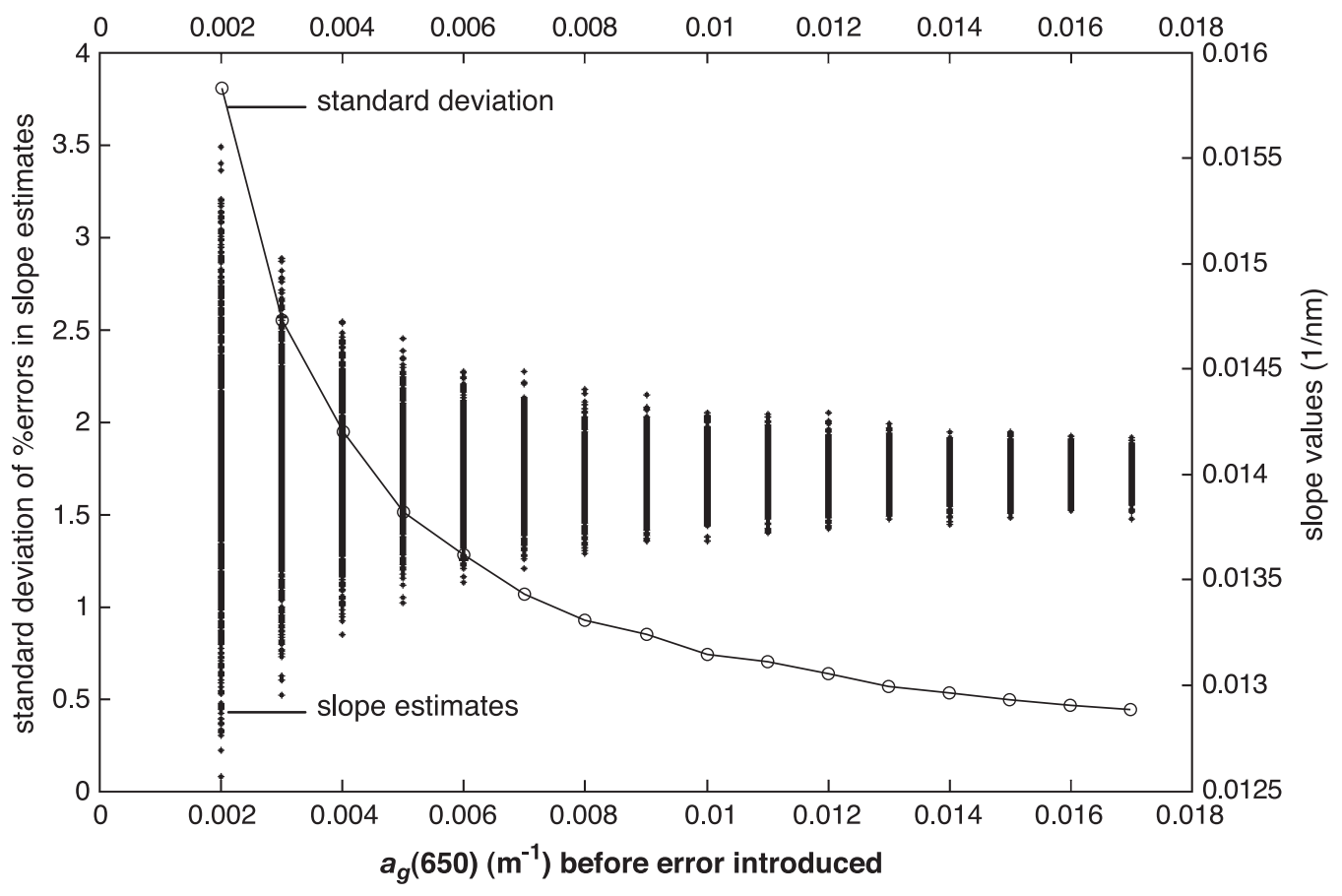

Fig. 2. The effect of bias errors in $a_{g}$ measurements with an ac9 on the estimate of a spectral slope with a single exponential model. Initial CDOM spectra varied in effective concentration with $a_{g}(650)$ ranging between 0.002 and $0.017 \mathrm{~m}^{-1}$, and with the slope constant at 0.014 $\mathrm{nm}^{-1}$. Spectral bias errors were added 1000 times for each initial spectrum (see text for details). Absorption values at the seven ac9 wavelengths from 412 through $650 \mathrm{~nm}$ were used. Using the criteria of $95 \%$ confidence that an estimate will fall within \pm 2 standard deviations of the mean for a normally distributed population, there will be $95 \%$ confidence that slope values will fall within about $\pm 5 \%$ ( 2 standard deviations) of the true value when $a_{g}(650)$ values approach $0.003 \mathrm{~m}^{-1}$.

$a_{g}$ values and the ac9 equivalent values increase with increasing $a_{g}$ levels, the increase in these differences has no effect on the spectral shape parameters (e.g., $s_{e}$ ). The spectral weighting of the ac9 spectral interference filters cannot, therefore, be expected to impart any dependence of the spectral shape parameters on $a_{g}$ magnitude.

\subsection{Fitting algorithm for models}

Models fits were applied by the nonlinear least squares minimization routine fminsearch in MATLAB (www.mathworks.com). Starting with "best guess" values for the variables, the routine iteratively searches for the minimum function using the Nelder-Mead simplex search method. MATLAB optimization parameters MaxFunEvals (maximum number of function evaluations allowed), MaxIter (maximum number of iterations allowed), TolX (ter- mination tolerance on the minimized function), and TolFun (termination tolerance on the function value) were set at $10^{10}, 10^{10}, 10^{-6}$, and $10^{-6}$, respectively.

\section{Results}

\subsection{Applying the single exponential model}

In evaluating the variation in the $s_{e}$ parameter in the literature the different fitting methods with respect to applying Eq. (1) or (2) will first be considered. In several cases, the exponential model is applied by taking the logarithm of CDOM absorption and then obtaining the slope parameter from a linear leastsquares fit (LLSM) of the resulting spectrum. However, this is not equivalent to fitting a single exponential (SEM) to the original spectrum by the least-squares method. The LLSM presupposes that the spectral 
errors after taking the logarithm of $a_{g}$ are spectrally constant and normally distributed, an invalid assumption. As a result, slope calculations for a dilution series would result in changing slope values for each diluted concentration (i.e., $s_{e}$ will be a function of amplitude), even though the composition of the CDOM pool was unchanged. The SEM, however, will show no dependency on the magnitude of absorption. In the majority of cases where $s_{e}$ is computed in the literature, the LLSM has been used or the fitting method is not specified (note that the exponential fitting routine in Microsoft Excel 2002 (under "chart/add trendline...") computes the regression with the incorrect LLSM, not the correct SEM). Differences in model results from applying the SEM and LLSM have recently been observed by Stedmon et al. (2000) and Blough and Del Vecchio (2002).

The disparity between the SEM and LLSM was apparent in slope values computed from $a_{g}(\lambda)$ data collected in the Narragansett Bay estuary with an ac9 (Fig. 3). This analysis is useful in quantifying the differences in slopes using the two methods in the context of the actual slope variability in a typical coastal estuary. Resulting differences between $s_{e}$ values from the two models were on the order of 0.002 $\mathrm{nm}^{-1}$, with the LLSM always computing a smaller slope than the SEM (the latter observation also made by Stedmon et al., 2000 and Blough and Del Vecchio, 2002). The magnitude of this difference is approximately eight times greater than the standard deviation around the mean of the results from the SEM. This difference is larger than the total deviation in $s_{e}$ values measured in samples from diverse marine sources by Zepp and Schlotzhauer (1981). Applying the LLSM therefore introduces large and unacceptable errors in determining $s_{e}$.

\subsection{The single exponential model (SEM) as a descriptor of $a_{g}(\lambda)$}

An implicit assumption in any comparison of $s_{e}$ values when applying a single exponential model is that the spectrum is exactly exponential over the spectral ranges considered. Therefore, the spectral range over which the slope is calculated should not be important. This was not the case, as illustrated in the absorption spectrum from a sample from Newport, OR (Fig. 4). More than $2 \times$ variability in the spectral slope parameter was observed depending on the different spectral ranges that were used in the fit.

When comparing the spectral ranges and slope values calculated from the single spectrum in Fig. 4

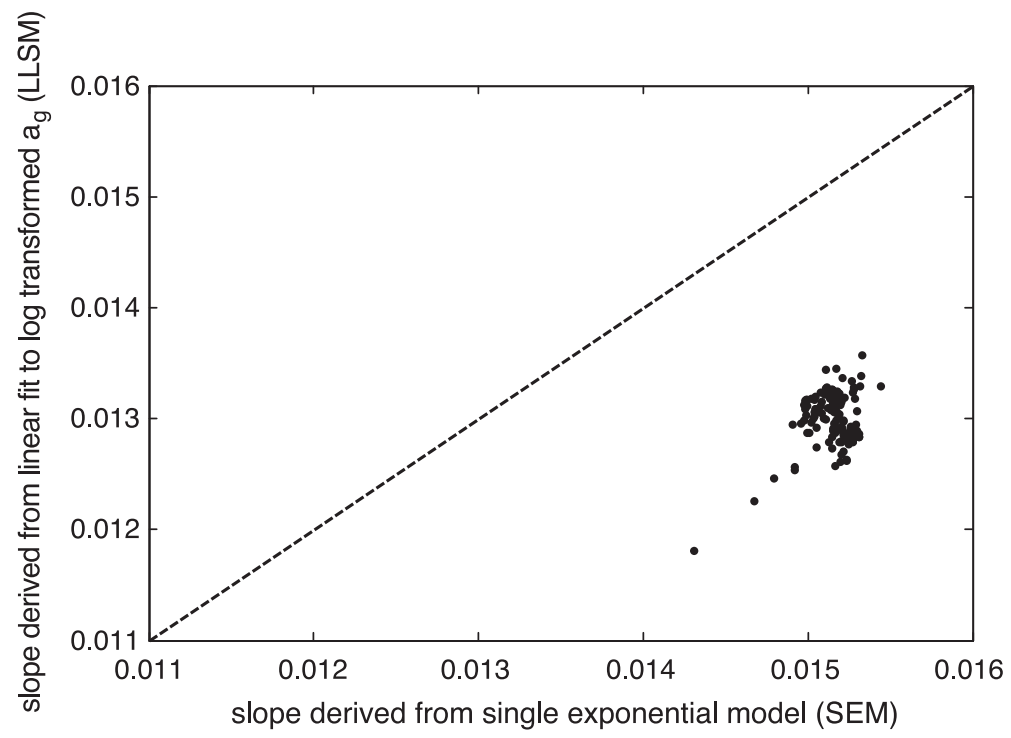

Fig. 3. The relationship between spectral slopes $\left(\mathrm{nm}^{-1}\right)$ calculated with a linear model after taking the logarithm (LLSM) and with an exponential least-squares fit (SEM) to the original spectra. CDOM absorption spectra were collected in Narragansett Bay with an in situ ac9. Original $a_{g}(412)$ ranged from 0.19 to $1.12 \mathrm{~m}^{-1}$ (see Fig. 6 for spectra). Dashed line is 1:1. 


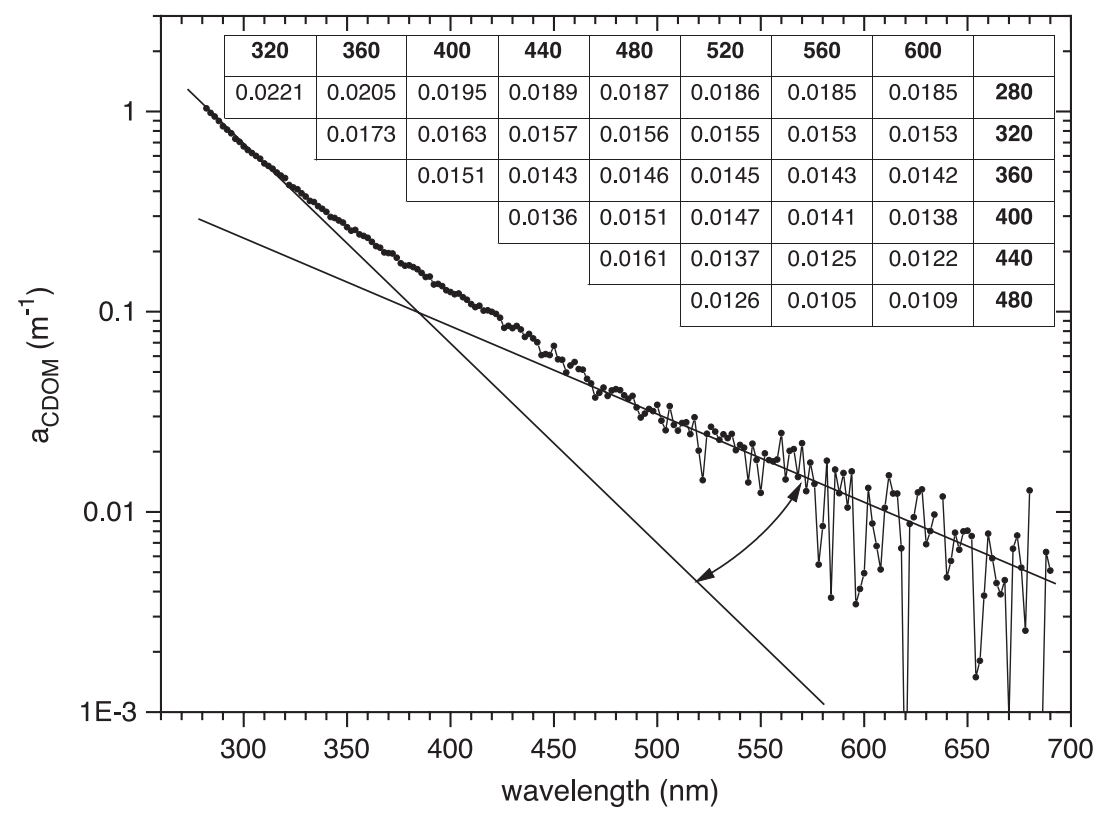

Fig. 4. Absorption spectrum of filtered Newport seawater plotted on a logarithmic scale. Lines demonstrate the range in exponential slope values that can be obtained with this single spectrum. Resulting slopes from a single exponential model (SEM) calculated over selected wavelength ranges are provided in the table inset, with starting wavelength of the range listed in the right column bold labels and ending wavelength in the top row bold labels.

with the globally collected data compiled in Table 1 , there are striking similarities. This is apparent when spectral slopes from the Newport, OR sample are calculated in the same spectral ranges used in the studies listed in Table 1 (in all cases where consistent ranges were used) and are regressed against the reported slopes (Fig. 5). Approximately $74 \%$ of the variability in the literature estimates of the spectral slope parameter could be explained by slope estimates computed over the same spectral ranges for this single CDOM absorption spectrum. Considering the many methodological differences between the different studies-including fitting method for the model (see previous section), the use or absence of various corrections for residual scattering in the filtrate, filter type and pore size used, and the variety of storage methods - the agreement is excellent. The residual scattering correction is particularly notable as in some cases it is applied as a baseline shift while in others it is given a spectral dependence (no correction was applied to the Newport spectrum) (see Sipelgas et al., 2000 for scattering correction methods comparison). These substantial methodological differences among studies would suggest that the similarity in the shape of CDOM absorption spectra from these studies is likely better than indicated here. The $\sim 26 \%$ unexplained variability is expected to relate to actual variability in the slope and, consequently, the composition of CDOM.

The reproducible pattern in slope values as a function of wavelength range observed throughout the literature suggests the SEM may not be the best descriptor for CDOM absorption spectra. Performance of the SEM as a general model for $a_{g}(\lambda)$ was evaluated in more detail by analyzing data sets of CDOM absorption spectra from six different regions around the coastal United States collected with an ac9 in the visible domain (Table 2, Fig. 2). Although extensive data sets exist that include CDOM absorption in the $\mathrm{UV}$, extending the analysis to shorter wavelengths is problematic because of the contribution of other absorbing substances besides CDOM (see Section 4 for further discussion). At this time, these different components cannot be reliably deconvolved to accurately isolate the CDOM contribution. Since the visible spectrum is also the range of interest for 


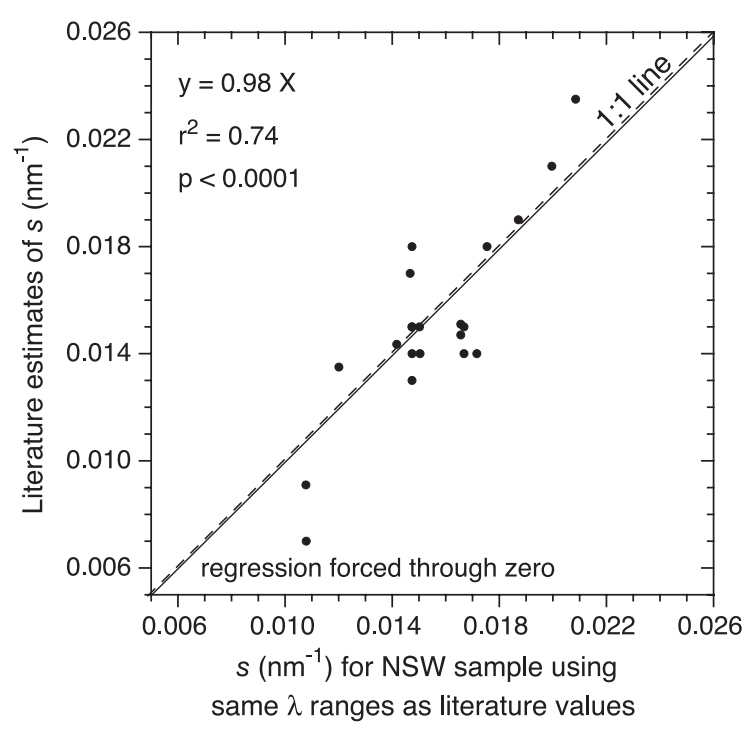

Fig. 5. Correlation between literature estimates of the slope and estimates from a single sample of Newport seawater (NSW) when wavelength ranges are matched (forced through origin).

remotely sensed ocean color work, the remaining analyses focus on the visible.

Measured CDOM absorption spectra and spectra normalized to spectral area to highlight variations in shape are plotted in Figs. 6 and 7 for the study sites. The SEM was applied to each of the spectra in Fig. 6, residuals were computed between the measured and modeled data, and the residuals were then normalized to the spectral area of the measured $a_{g}(\lambda)$ for intercomparison (Fig. 8). The residuals show a clear pattern, where, from about 440 to $500 \mathrm{~nm}$, residuals are typically negative from modeled values consistently being higher than the measured values. Longer than $500 \mathrm{~nm}$, residuals are consistently positive, indicating the modeled values are too low. Such a pattern is an indication that greater curvature is needed in a spectral model describing $a_{g}(\lambda)$.

For the ES, GOMFL, GOMLA, and NB data sets, slope values fell within a narrow range, with a combined mean and standard deviation of $0.0152 \pm 0.0005 \mathrm{~nm}^{-1}$. Results from the MB and PAP data fell out of this range, with slope values of $0.0127 \pm 0.0006$ and $0.0164 \pm 0.0002 \mathrm{~nm}^{-1}$ for the $\mathrm{MB}$ and PAP data, respectively. The deviation of the slopes of these two data sets from the range of the other data suggests compositional differences in the
CDOM pools of $\mathrm{MB}$ and PAP relative to the other regions. For the entire data set, the mean and standard deviation of the slope was $0.0150 \pm 0.0009 \mathrm{~nm}^{-1}$. As a function of depth, the spectral slope parameter consistently followed a trend of steadily increasing toward the surface at all sites studied (plot not shown), in agreement with observations by Vodacek et al. (1997) and Twardowski and Donaghay (2002) and the notion that solar photobleaching results in a steepening of the CDOM spectrum.

\subsection{Considering other models to describe CDOM absorption spectra}

While there is a theory in place to qualitatively describe the observation of monotonically decreasing absorption with increasing wavelength (Shifrin, 1988), directly applying this model to CDOM absorption spectra is not possible without a knowledge of the size distribution, or more specifically the distribution of carbon chain lengths, of the organic complexes comprising a CDOM pool. Thus, regardless of the desire to attach some theoretical justification to a spectral model, CDOM absorption can only be described by purely empirical methods at this time.

Five additional models were considered to describe observed $a_{g}(\lambda)$ in the visible (Table 3 ). These models were chosen based on their potential to provide more curvature to modeled spectra than the SEM while minimizing an increase in the number of modeled parameters (determines degrees of freedom of the model). Two criteria were used to determine usefulness of a given model: (1) the magnitude of the $F$ statistic from an Analysis of Variance (ANOVA) (McClave and Dietrich, 1988), and (2) the tendency to show random patterns in the spectra of the residuals between the modeled and measured values. The $F$ parameter is computed as:

$F=\frac{R^{2} / D_{\mathrm{m}}}{\left(1-R^{2}\right) / D_{\mathrm{e}}}$

where $R^{2}$ is the correlation coefficient for the regression from a least-squares fit, $D_{\mathrm{m}}$ is the degrees of freedom of the model, and $D_{\mathrm{e}}$ is the degrees of freedom of the error or unexplained variability. If the number of model parameters is $p$, and the number of data points used in the fit is $n, D_{\mathrm{m}}$ is $(p-1)$ and $D_{\mathrm{e}}$ 

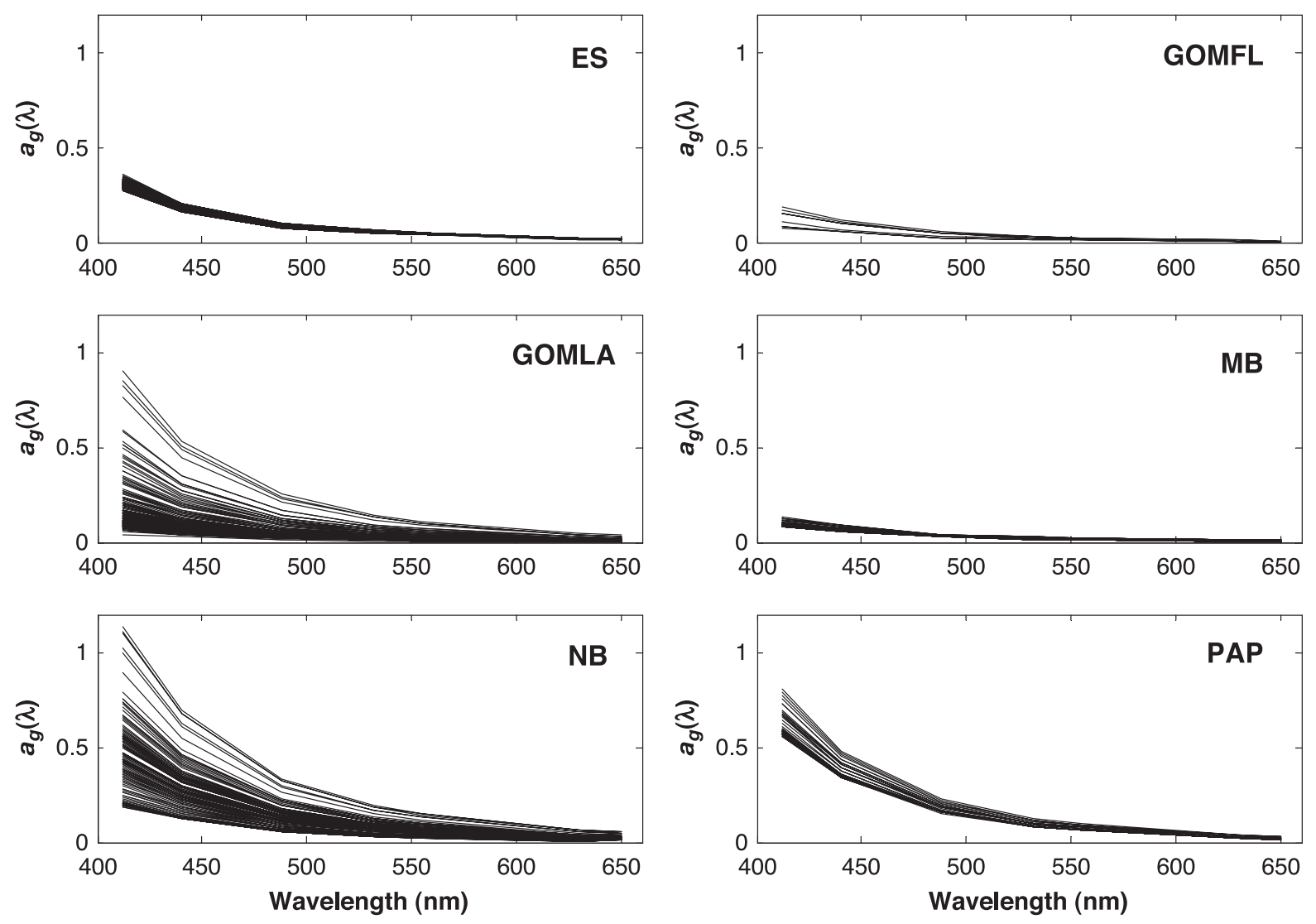

Fig. 6. All measured $a_{g}(\lambda)\left(\mathrm{m}^{-1}\right)$ for each study site, with linear interpolation between the seven ac9 values from 412 to $650 \mathrm{~nm}$.

is $(n-p)$. While the $R^{2}$ is an indicator of how well the model fits the data, the $F$ parameter provides a better test of the usefulness of the model based on the number of data points used in the fit and the number of model parameters. A good model should have as few parameters as possible while exhibiting a high correlation coefficient. A high $R^{2}$ alone is insufficient as a determiner. This is illustrated in the case where a sixth order polynomial is fit to the ac9 CDOM spectra considered here, which consist of seven points. The $R^{2}$ for this model will be 1 , but the model is not useful as a descriptor of CDOM absorption spectra.

Each of the models in Table 3 were fit to each of the spectra in Fig. 6, residuals were computed between the measured and modeled data, and the residuals were then normalized to the spectral area of the measured $a_{g}(\lambda)$ for intercomparison (Fig. 9). Each of the models displayed less consistent patterns than the SEM, with the exception of the DEM, where the results were very similar to the SEM. The second exponential term of the DEM apparently provided no significant improvement in the fit. The models showing the least pattern in residuals were the HM and the SEM-O, with 2 and 3 model parameters, respectively. The lowest normalized residuals were observed with the DEM-F, although there were consistent patterns in the residual spectra shorter than $532 \mathrm{~nm}$. The fixed value of the second slope (held constant here at 0.010 $\mathrm{nm}^{-1}$ ) of the DEM-F was also varied between 0.002 and $0.030 \mathrm{~nm}^{-1}$ without any significant change in the magnitude or pattern of the residuals (data not shown).

Means, standard deviations, and medians of the $F$ statistic for each model applied to CDOM absorption spectra from each study region are provided in Table 4. Since means can be strongly affected by a few spectra with very high or very low values, the median $F$ value is used as a better measure of model "use- 


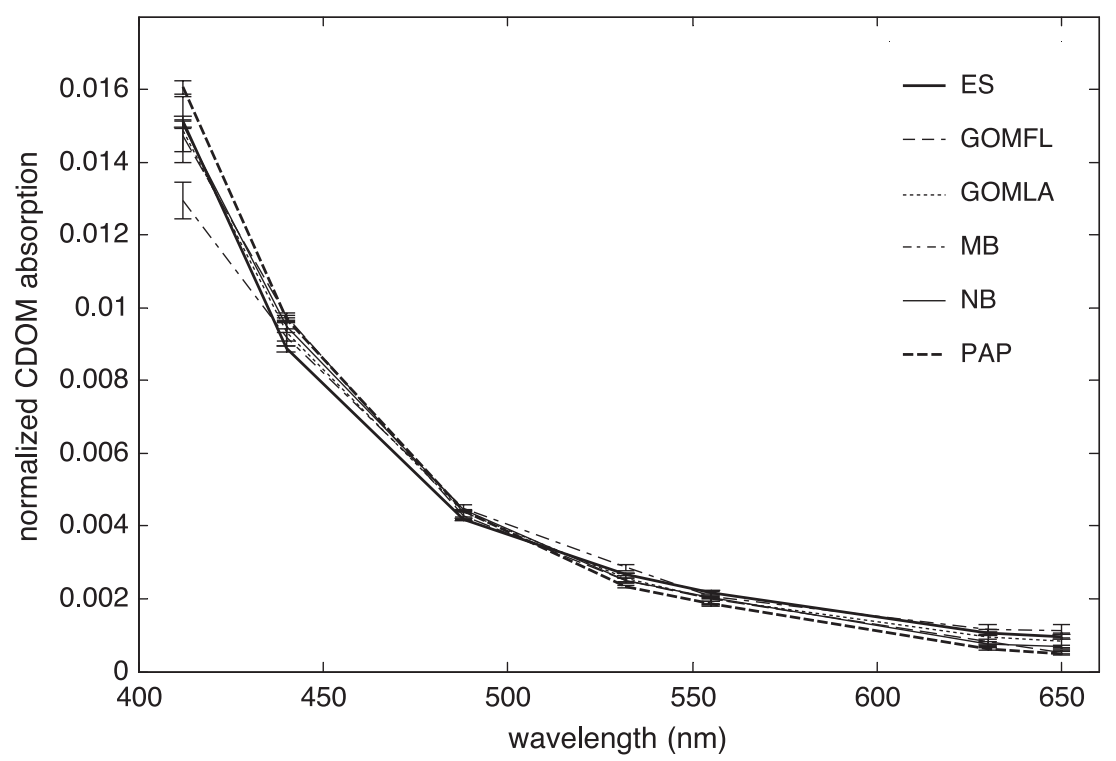

Fig. 7. All $a_{g}(\lambda)$ for each study site, normalized to spectral area for intercomparison. Error bars are standard deviations.

fulness." The DEM consistently ranks last or next to last in this respect, supporting the observation from the residual analysis that the second exponential provides little improvement in fitting the spectra (the higher the $F$ value, the more "useful" the model).
Overall, the SEM performs second worst, ranking 4th or 5 th out of the six models.

No one model stands out as consistently the best, but overall, the HM is the top performer, with 3 top rankings, 2 second rankings, and 1 third ranking.

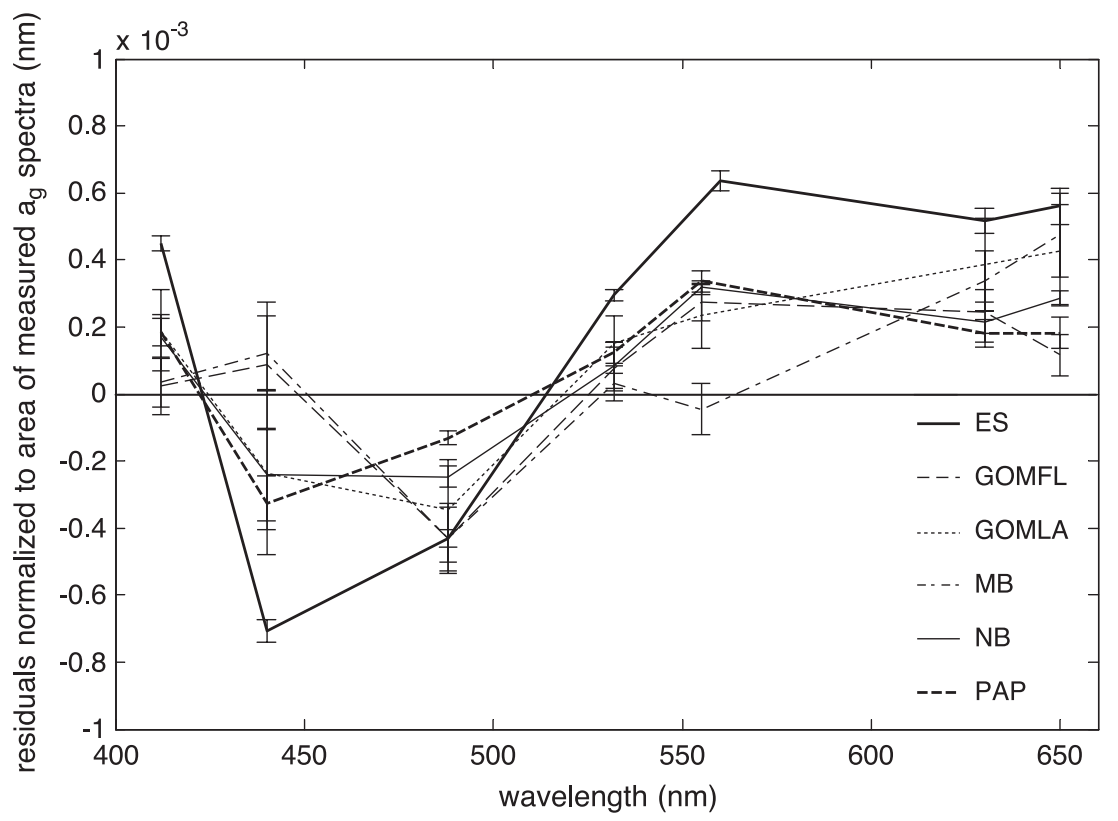

Fig. 8. Residuals normalized to the area of measured $a_{g}(\lambda)$ for the single exponential model (SEM). Error bars are standard deviations. 
Table 3

The six models considered as descriptors of CDOM absorption spectra in this study

\begin{tabular}{lll}
\hline Model & Function & Modeled parameters \\
\hline Single exponential (SEM) & $y=A \mathrm{e}^{-s_{e} \lambda}$ & $A, s_{e}$ \\
Single exponential, function of wavenumber (SEM-W) & $y=A \mathrm{e}^{-s_{w} / \lambda}$ & $A, s_{w}$ \\
Hyperbolic (HM) & $y=A((\lambda) /(532))^{-s_{h}}$ & $A, s_{h}$ \\
Single exponential, with offset (SEM-O) & $y=A \mathrm{e}^{-s_{o} \lambda}+O$ & $A, O, s_{o}$ \\
Double exponential, one slope fixed (DEM-F) & $y=A_{1} \mathrm{e}^{-s_{1} \lambda}+A_{2} \mathrm{e}^{-0.010 \lambda}$ & $A_{1}, A_{2}, s_{1}$ \\
Double exponential (DEM) & $y=A_{1} \mathrm{e}^{-s_{1} \lambda}+A_{2} \mathrm{e}^{-s_{2} \lambda}$ & $A_{1}, A_{2}, s_{1}, s_{2}$ \\
\hline
\end{tabular}

Even for the ES data set, where the HM ranked third, it did substantially better than the SEM. This agrees with the lack of a consistent spectral pattern in the residuals observed in applying the HM to the six data sets (Fig. 9). The improved fit is also evident in the variability in computed hyperbolic slopes versus exponential slopes for the different spectral ranges in the visible region tested in Fig. 4 with the sample from Newport. In the visible, the standard deviation of the exponential slopes was $13 \%$ of the mean (averaging all slope values from Fig. 4 computed over the visible range), as opposed to $8 \%$ for the hyperbolic slopes (data not shown). This indicates that different spectral ranges chosen in the fit introduce less error with the
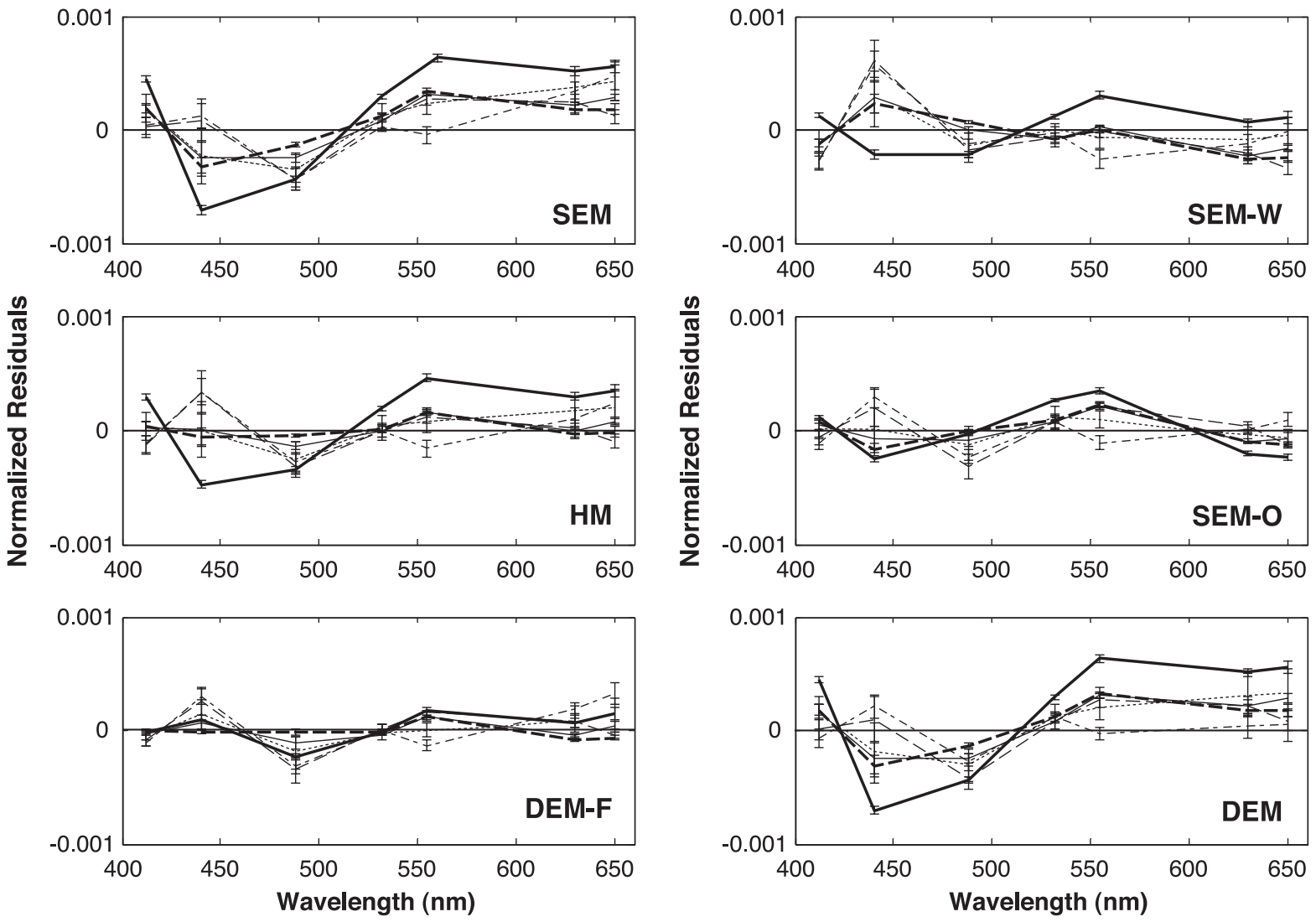

Fig. 9. Area-normalized residuals for $a_{g}(\lambda)$ after applying the six models in Table 3 for each study region. Residual averages are plotted with standard deviations as error bars. Same legend as in Fig. 8. 
Table 4

$F$-statistic mean, standard deviation, and median results for the CDOM absorption spectral models applied to data from each study site

\begin{tabular}{llrrrrrr}
\hline Site & Parameter & \multicolumn{6}{c}{ Model } \\
\cline { 3 - 8 } & & SEM & SEM-W & HM & SEM-O & DEM-F & DEM \\
\hline ES & mean & 414 & 3614 & 937 & 899 & 2708 & 102 \\
& std & 47 & 1036 & 153 & 134 & 738 & 55 \\
& median & 409 & 3341 & 915 & 873 & 2550 & 84 \\
GOMFL & mean & 2547 & 1614 & 4237 & 1797 & 2112 & 524 \\
& std & 1375 & 1022 & 2854 & 930 & 1345 & 267 \\
& median & 1960 & 1225 & 3765 & 2079 & 2061 & 429 \\
GOMLA & mean & 1504 & 10,218 & 7370 & 3969 & 15,077 & 879 \\
& std & 1233 & 15,158 & 12,763 & 3749 & 35,808 & 2832 \\
& median & 1309 & 5230 & 3805 & 2988 & 2383 & 293 \\
MB & mean & 1350 & 1305 & 1937 & 1546 & 796 & 801 \\
& std & 1180 & 579 & 769 & 850 & 530 & 401 \\
& median & 951 & 1182 & 1665 & 1250 & 641 & 720 \\
NB & mean & 2195 & 6185 & 13,126 & 3416 & 15,830 & 529 \\
& std & 574 & 3952 & 6052 & 683 & 12,876 & 1026 \\
& median & 2197 & 5172 & 12,032 & 3372 & 14,653 & 443 \\
PAP & mean & 3103 & 5853 & 25,085 & 3467 & 16,552 & 883 \\
& std & 1169 & 3139 & 9793 & 1133 & 7968 & 1802 \\
& median & 2852 & 4788 & 24,870 & 3095 & 13,010 & 593 \\
\hline
\end{tabular}

HM as opposed to the SEM. It is important to note, however, that the HM still exhibits a non-negligible dependency on the spectral range considered.

Distributions of the hyperbolic slopes computed for the different study sites generally grouped around 7.0, with the MB and PAP data falling consistently below and above 7.0, respectively (Fig. 10). Again, this would suggest real compositional differences in the CDOM pool between MB, PAP, and the other study regions.

In several past studies, offsets, usually derived from absorption values in the long wavelength visible and infrared (IR), have been subtracted from absorption spectra before applying the SEM. This is typically performed to remove potential scattering errors attributed to differences in sample and blank refractive indices or small particles remaining in the filtered solution. The SEM-O evaluated here is similar to this method, but the offset is derived from the leastsquares fit of the model (as in Stedmon et al., 2000; Stedmon and Markager, 2001). In this manner, the fitted offset is simply another parameter-another degree of freedom - relative to the SEM model. These fitted offsets, however, were in general agreement with what one would consider a baseline offset derived from the signal in the near-IR region of the spectrum. Therefore, comparing the fitted slopes between the SEM and SEM-O provides a means of estimating the effect of subtracting an offset on the slope parameter.

The slopes derived from the SEM-O are provided in Fig. 11. In all cases, the slopes are higher than the slopes derived from the SEM. This result was also observed by Stedmon et al. (2000) in samples from Danish fjords and Sipelgas et al. (2000) in samples from Estonian and Finnish lakes. The average $s_{o}$ for the full data set here was $0.0184 \pm 0.0017 \mathrm{~nm}^{-1}$, compared to $0.0150 \pm 0.0009 \mathrm{~nm}^{-1}$ for $s_{e}$. Therefore, slopes computed from spectra with and without a spectrally constant offset are not comparable. This is partly because some absorption by CDOM is present in the long wavelength region of the visible.

A Gaussian model to describe CDOM absorption (Gege, 2000; Schwarz et al., 2002) was also attempted, but because of the spectral range considered and the number of data points that were used, the model did not reliably converge and could not be used.

The applicability of these results to CDOM absorption spectra collected with higher resolution than an ac9 was also evaluated, but in a far less comprehensive manner. High-resolution (2-nm interval) absorption spectra from East Sound, WA and Newport, OR were modeled. Since CDOM absorption spectra are monotonic functions, it was expected that results should be similar when using the same spectral range, and preliminary results confirm that expectation. Using the same spectral range as in the ac9 analyses $(412-650 \mathrm{~nm})$, the HM exhibited the highest $F$ value for the East Sound sample. The highest $F$ values for Newport were obtained with both the HM and SEMW (agreed within 5\%).

\section{Discussion}

\subsection{Evaluation of the single exponential model (SEM)}

The magnitude of an absorption spectrum of the dissolved fraction of seawater may be used as a proxy for the concentration of CDOM, and the shape may be used as a proxy of the composition of CDOM, including the ratio of fulvic acids to humic acids, 

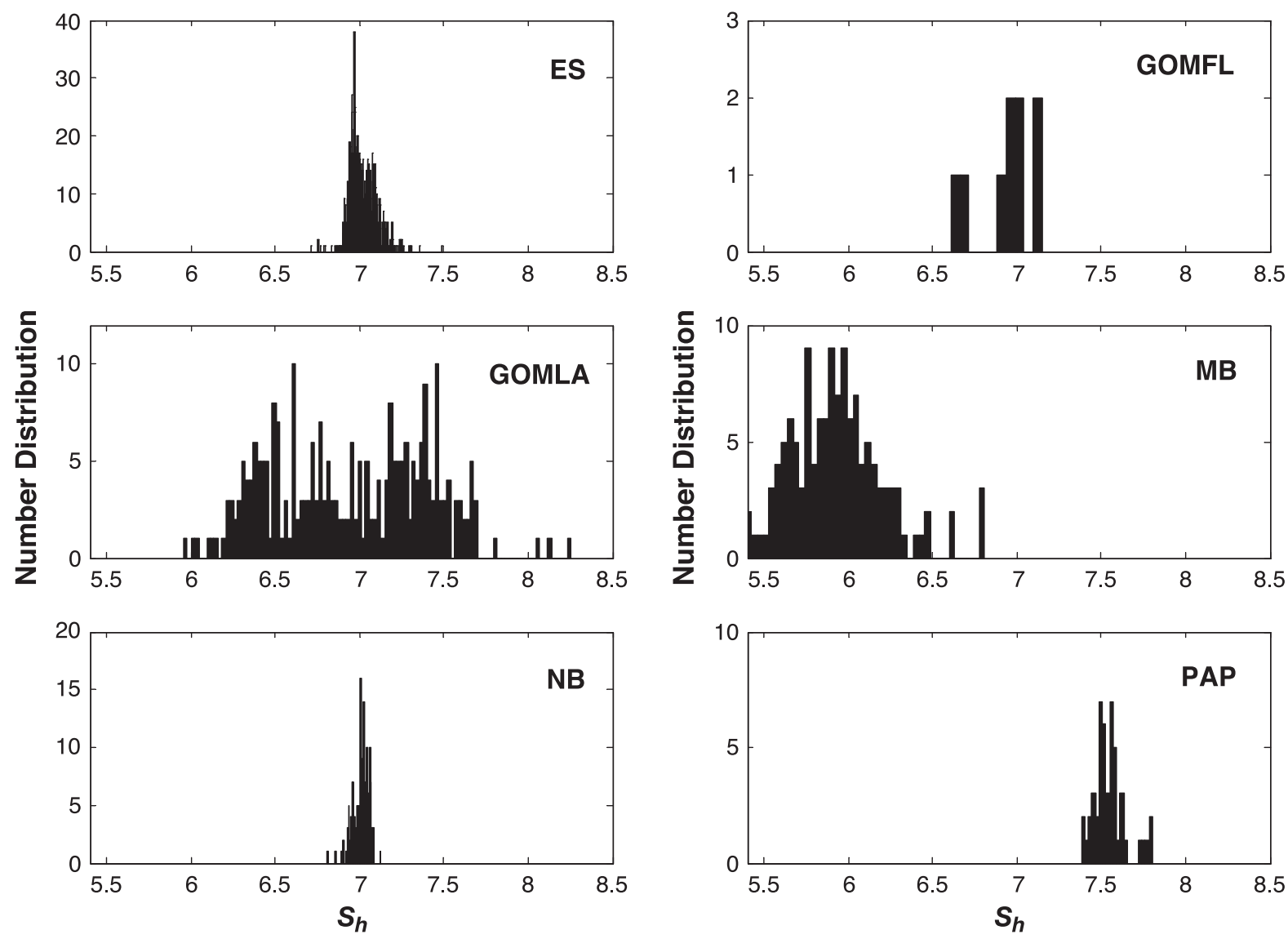

Fig. 10. Distribution of hyperbolic slopes (unitless) computed from the HM for each study site.

molecular weight distribution, and aromaticity (Blough and Green, 1995). To make accurate interpretations, however, an accurate spectral model is needed and relationships must be derived between parameters in a spectral model and the physicalchemical properties of CDOM. Knowing such relationships may then be useful in furthering an understanding of how CDOM interacts with its environment (e.g., Blough and Green, 1995). The first step, however, is determining an accurate, descriptive spectral model and the limitations of its application.

From the analysis of measurements presented herein and data reported in the literature, it is demonstrated that the shape of the spectrum for CDOM absorption is relatively consistent among widely varying regions. Almost three-quarters of the vari- ability in the single exponential slope in the literature could be attributed to the spectral range that was used in the fit. The higher values found in more recent works can be attributed to an increasing focus on CDOM absorption at shorter wavelengths extending into the UV where a significantly higher signal to noise is observed. Higher values may also be attributed to the use of the SEM model after subtracting a baseline. The implication from this analysis is that CDOM composition is more consistent than currently thought.

This should not obfuscate the fact that variability in CDOM composition, evidenced from variability in SEM slopes computed within constant spectral ranges, certainly does occur. One key process known to cause such variability is photobleaching (e.g., Kieber et al., 1990; Vodacek et al., 1997; Blough 

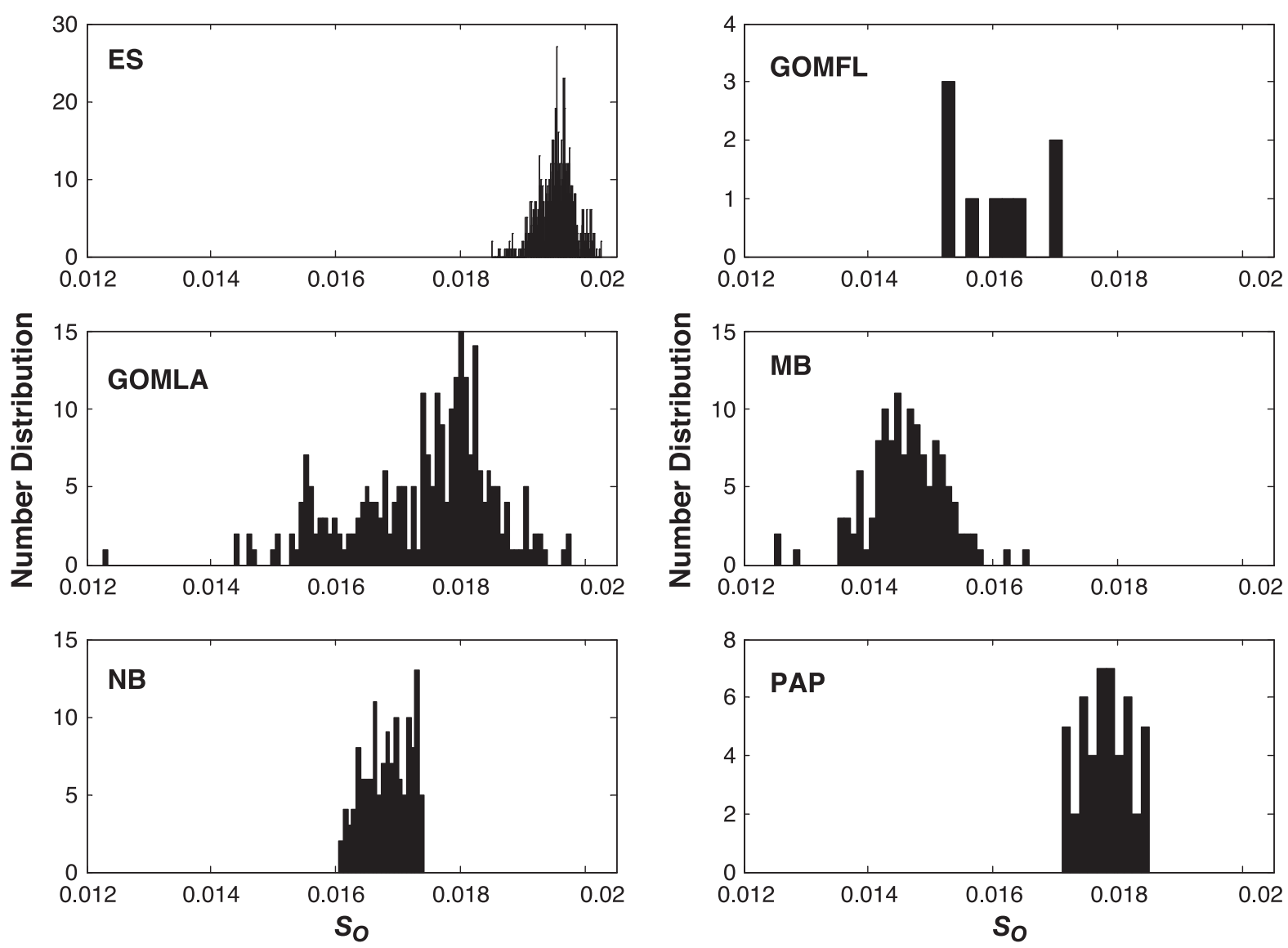

Fig. 11. Distribution of slopes $\left(\mathrm{nm}^{-1}\right)$ computed from the SEM-O for each study site.

and Del Vecchio, 2002; Twardowski and Donaghay, 2002; Whitehead et al., 2002). Photobleaching appears to cause a shift from large molecular weight CDOM complexes absorbing at longer wavelengths to smaller complexes absorbing at shorter wavelengths, thus increasing the spectral slope (Whitehead et al., 2002; Twardowski and Donaghay, 2002).

In the data set from six regions considered here, the highest slope values in all regions were observed at the surface, supporting the hypothesis that photobleaching increases the slope. The very highest slope values calculated over the 412 to $650 \mathrm{~nm}$ spectral range were around $0.018 \mathrm{~nm}^{-1}$ and the lowest were around $0.012 \mathrm{~nm}^{-1}$, although in any one region variability in the slope parameter was typically much less. For the ES, GOMFL, GOMLA, and NB data sets, slope values fell within a narrow range, with a combined standard deviation of only \pm 0.0005 $\mathrm{nm}^{-1}$. Changes in the slope in the visible range that have been attributed to photobleaching are on the order of $0.001-0.002 \mathrm{~nm}^{-1}$ (Twardowski and Donaghay, 2002), consistent with the range of variability observed.

The SEM slope values for the PAP and MB data sets fell outside the range observed for the other regional data sets, suggesting a relative difference in CDOM composition in these regions. Photobleaching, differences in CDOM source composition, and/or other factors may be responsible. More work is needed to better interpret these differences.

As noted in previous studies, application of the single exponential model over different spectral ranges resulted in different fitted slopes. The reproducible pattern in slope values computed over differ- 
ent spectral ranges was reflected as a consistent pattern in the residuals (Fig. 8). In thorough works investigating spectral CDOM absorption (Bricaud et al., 1981; Carder et al., 1989) the spectral dependency of the SEM was recognized. It is explicitly stated by Carder et al. (1989) that the single exponential spectral slope parameter is "...dependent on the spectral portion of the curve being fit." Therefore, interpreting any spectral slope information in the context of previous works requires careful consideration of the spectral range. Although the issue has normally not been addressed in calculations of the spectral slope in the literature, there are notable recent exceptions (Del Castillo et al., 1999; Gege, 2000; Sipelgas et al., 2000; Stedmon et al., 2000; Stedmon and Markager, 2001; Blough and Del Vecchio, 2002; Schwarz et al., 2002).

To extend the modeling analysis of CDOM spectra into the UV less than about $350 \mathrm{~nm}$, consideration must be given to other substances present in the dissolved fraction of seawater that begin to absorb intensely. Most notably, these include oxygen, bromide, nitrate, and sea salts (e.g., Shifrin, 1988). Thus, spectral slopes computed over a range including this region will be influenced from the absorption of these substances. The presence of strong absorbers besides CDOM is supported by the observation that fluorescence excitation spectra for CDOM, a proxy for absorption spectra, typically show a peak around 290-350 nm with a drop-off at shorter wavelengths (Coble, 1996). Shoulders that correspond with the range of this excitation peak are sometimes observed in absorption spectra, but typically UV absorption spectra continue to sharply increase with decreasing wavelength. The absorption by other dissolved components of seawater besides CDOM may explain the observation of greater variability in the exponential spectral slope when it is computed over this range (see Table 1).

Moreover, the interference of other absorbing substances hinders analysis of the CDOM absorption spectrum in the UV at this time. To accurately determine CDOM absorption in the UV, the contribution from other dissolved components must be deconvolved from the spectra. Derivative methods or fitting routines such as the Gaussian method proposed by Gege (2000) may prove useful in this pursuit.

\subsection{The most "useful" model for describing $a_{g}$ spectra}

Overall, the most statistically useful model in the visible range found in this study was the hyperbolic model (HM). For the HM, the $F$ statistic was significantly improved over the SEM on a consistent basis for the spectra from all sites studied. Thus, a conclusion of this work is that the HM is preferred over the SEM for describing CDOM spectra in the visible. Like the SEM, the HM also has the convenience of describing the shape of a CDOM spectrum with only one parameter, the hyperbolic slope. The overall combined mean and standard deviation for the hyperbolic slopes from the full set of absorption spectra was $6.92 \pm 0.39$.

The HM model also performed better than the SEM with respect to dependence on spectral range, although spectral range was still important. Thus, in reporting CDOM fitting results with any of the models considered here, disclosing spectral range is necessary to allow accurate comparison with other measurements.

Although the performance of the HM was better, the large literature base and historical precedence for using the SEM will provide momentum for its continued use. Indeed, consistently using the correct SEM with a constant spectral range remains an effective method of gauging variability in CDOM composition. The assertion that continuing to apply the SEM will allow comparison with the extensive body of previous work, however, is somewhat dubious because the different spectral ranges and the many different applications of the single exponential type model bring into question any such comparison. At the very least, caution should be exercised.

\subsection{Application to remote sensing models}

Satellite ocean color sensors (MODIS, SEAWifs, etc.) have bands in the short wavelength visible (between 400 and $412 \mathrm{~nm}$ ) that may be used to estimate $a_{g}$ distinct from other in-water constituents (Carder et al., 1991, 1999). Several semi-analytical models require that $a_{g}$ in the short wavelength visible then be extrapolated to the rest of the visible in order to estimate chlorophyll concentrations and potentially productivity using derived phytoplankton absorption 
spectra (Carder et al., 1991, 1999; Roesler and Perry, 1995). This requires a detailed knowledge of the spectral shape of absorption in the visible and its consistency regionally. From the conclusion of this work, there appears to be reasonable consistency in the shape of the CDOM absorption spectrum in the visible region in a wide range of natural waters. Thus, using a single spectral shape in the visible that can be scaled with the absorption derived from a remotely sensed signal at one wavelength in the blue may have merit in many cases. A generic, representative CDOM absorption model from this study which requires one absorption estimate at $412 \mathrm{~nm}$ as input is:

$a_{g}(\lambda)=a_{g}(412)\left(\frac{\lambda}{412}\right)^{-6.92}$

Absolute residuals between this model and all spectra from the six data sets were generally less than 0.01 $\mathrm{m}^{-1}$ (Fig. 12). The largest residuals were observed for the PAP data because the PAP data had relatively high CDOM absorption signals. The average residual as a percentage of average measured absorption at $488 \mathrm{~nm}$ (wavelength where largest absolute residuals were observed) was $12 \%$. Such errors are relatively small and could be acceptable for many remote sensing applications, particularly in coastal regions.

\section{Conclusions}

- The composition of the CDOM pool is more consistent than currently thought.

- The majority of variability in previous slope estimates can largely be explained by the differences in spectral range used in the fit. Additional variability can be attributed to misapplication of the model (e.g., the LLSM) or application of a similar, but different model (e.g., the SEM-O).

- All prospective CDOM absorption models considered were more useful descriptors statistically than the single exponential model, with the exception of the DEM.

- A hyperbolic model (HM) was statistically the most useful descriptor of CDOM absorption spectra. The wavelength range over which the model is applied is still important, however.

- The single spectral slope can be used to glean information on CDOM composition if the same wavelength range is always used and the SEM is applied.

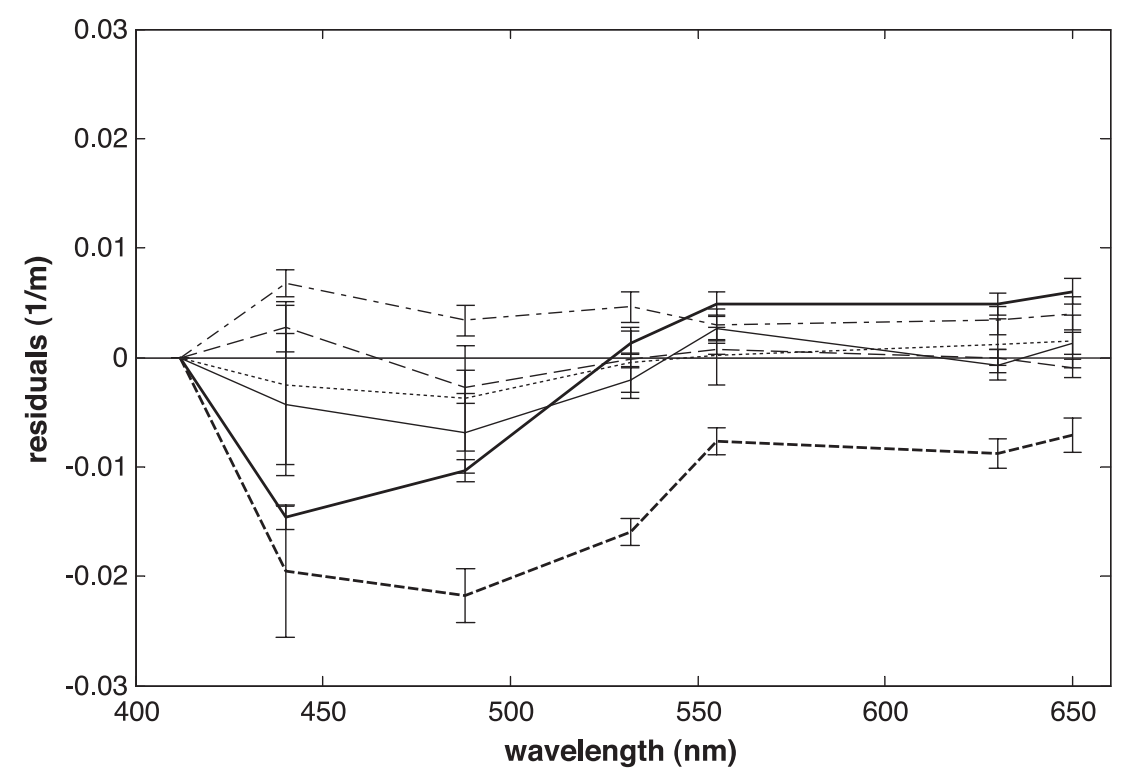

Fig. 12. Residuals with standard deviations from applying a representative hyperbolic spectral model (Eq. (4)) to CDOM absorption spectra from each data set. Same legend as in Fig. 8. 
- Care should be exercised to make certain fitting algorithms are known when using "black box" regression routines such as those in Microsoft Excel.

\section{Acknowledgements}

Special thanks to S. Freeman for help in the field and with data processing. The use of the Cary spectrophotometers at WET Labs and Jim Ingle's lab at Oregon State U. is much appreciated. The authors are indebted to J.R.V. Zaneveld, K. Shifrin, and W.S. Pegau for many stimulating discussions on CDOM. Support is acknowledged from ONR Environmental Optics (M.S.T. and E.B.), ONR Biology and Chemistry (P.LD.), NSF Instrumentation (P.L.D.) and a WET Labs postdoctoral fellowship (M.S.T.).

\section{References}

Aas, E., 2000. Spectral slope of yellow substance: problems caused by small particles. Proc. Ocean Optics XV, Monaco, 16-20 October Office of Naval Research, USA CD-ROM.

Blough, N.V., Del Vecchio, R., 2002. Distribution and dynamics of chromophoric dissolved organic matter (CDOM) in the coastal environment. In: Hansell, D.A., Carlson, C.A. (Eds.), Biogeochemistry of marine dissolved organic matter. Academic Press, New York, p. 500.

Blough, N.V., Green, S.A., 1995. Spectroscopic characterization and remote sensing of non-living organic matter. In: Zepp, R.G., Sonntag, Ch. (Eds.), The Dahlem Workshop on the Role of Nonliving Organic Matter in the Earth's Carbon Cycle, Berlin, 1993. Wiley, New York, pp. 23-45.

Blough, N.V., Zafiriou, O.C., Bonilla, J., 1993. Optical absorption spectra of waters from the Orinoco River outflow: terrestrial input of colored organic matter to the Caribbean. J. Geophys. Res. 98, 2271-2278.

Bricaud, A., Morel, A., Prieur, L., 1981. Absorption by dissolved organic matter in the sea (yellow substance) in the UV and visible domains. Limnol. Oceanogr. 28, 43-53.

Brown, M., 1977. Transmission spectroscopy examinations of natural waters: c. Ultraviolet spectral characteristics of the transition from terrestrial humus to marine yellow substance. Estuar. Coast. Mar. Sci. 5, 309-317.

Bushaw, K.L., et al., 1996. Photochemical release of biologically available nitrogen from aquatic dissolved organic matter. Native 381, 404-407.

Carder, K.L., Steward, R.G., Harvey, G.R., Ortner, P.B., 1989. Marine humic and fulvic acids: their effects on remote sensing of ocean chlorophyll. Limnol. Oceanogr. 34, 68-81.

Carder, K.L., Hawes, S.K., Baker, K.A., Smith, R.C., Steward,
R.G., Mitchell, B.G., 1991. Reflectance model for quantifying chlorophyll a in the presence of productivity degradation products. J. Geophys. Res. 96, 20599-20611.

Carder, K.L., Chen, F.R., Lee, Z.P., Hawes, S., Kamykowski, D., 1999. Semi-analytic MODIS algorithms for chlorophyll $a$ and absorption with bio-optical domains based on nitrate-depletion temperatures. J. Geophys. Res. 104 (C3), 5403-5421.

Ciotti, A.M., Cullen, J.J., Lewis, M.R., 1999. A semi-analytical model of the influence of phytoplankton community structure on the relationship between light attenuation and ocean color. J. Geophys. Res. 104, 1559-1578.

Coble, P., 1996. Characterization of marine and terrestrial DOM in seawater using excitation-emission matrix spectroscopy. Mar. Chem. 51, 325-346.

Davies-Colley, R.J., 1992. Yellow substance in coastal and marine waters round the South Island, New Zealand. N.Z. J. Mar. Freshw. Res. 26, 311-322.

Del Castillo, C.E., Coble, P.G., Morell, J.O., Lopez, J.M., Corredor, J.E., 1999. Analysis of the optical properties of the Orinoco River plume by absorption and fluorescence spectroscopy. Mar. Chem. 66, 35-51.

Donaghay, P.L., Rines, H.M., Sieburth, J.McN., 1992. Simultaneous sampling of fine scale biological, chemical, and physical structure in stratified waters. Arch. Hydrobiol., Beih. 36, 97-108.

Efron, B., Tibshirani, R., 1986. Bootstrap methods for standard errors, confidence intervals, and other measures of statistical accuracy. Stat. Sci. 1, 54-77.

Gege, P., 2000. Gaussian model for yellow substance absorption spectra. Proc. Ocean Optics XV, Monaco, 16-20 October. Office of Naval Research, USA CD-ROM.

Green, S.A., Blough, N.V., 1994. Optical absorption and fluorescence properties of chromophoric dissolved organic matter in natural waters. Limnol. Oceanogr. 39, 1903-1916.

Højerslev, N.K., Aas, E., 2001. Spectral light absorption by yellow substance in the Kattegat-Skagerrak area. Oceanologia 43, $39-60$.

Jerlov, N.G., 1976. Optical Oceanography. Elsevier, New York. 194 pp.

Kalle, K., 1966. The problem of Gelbstoff in the sea. Oceanogr. Mar. Biol. Annu. Rev. 4, 91-104.

Kieber, R.J., Zhou, X., Mopper, K., 1990. Formation of carbonyl compounds from UV-induced photodegradation of humic substances in natural waters: fate of riverine carbon in the sea. Limnol. Oceanogr. 35 (7), 1503-1515.

Kopelevich, O.V., Burenkov, V.I., 1977. Relation between the spectral values of the light absorption coefficients of sea water, phytoplankton pigments, and the yellow substance. Oceanology $17,278-282$.

Kowalczuk, P., 1999. Seasonal variability of yellow substance absorption in the surface layer of the Baltic Sea. J. Geophys. Res. 104 (C12), 30047-30058.

Kowalczuk, P., Olszewski, J., Darecki, M., Kaczmarek, S., 2003. Empirical relationships between Coloured Dissolved Organic Matter (CDOM) absorption and apparent optical properties in Baltic Sea waters. Int. J. Remote Sens. (in press).

Maske, H., Pegau, W.S., Zaneveld, R., Duarte, R.C., 1998. Photo- 
bleaching of colored dissolved organic matter (CDOM) and the temporal and spatial variability of CDOM in the Gulf of California. Proc. Of "The 4th Pacific Ocean Remote Sensing Conference," Qingdao, China, July 28-31.

McClave, J.T., Dietrich II, F.H. 1988. Statistics. Dellen Publishing, San Francisco, CA. 1014 pp.

Miller, W.L., 1998. Effects of UV radiation on aquatic humus: photochemical principles and experimental considerations. In: Hessen, W.L., Tranvik, L. (Eds.), Ecological Studies. Aquatic Humic Substances, vol. 133. Springer-Verlag, New York, pp. 125-143.

Nelson, N.B., Siegel, D.A., Michaels, A.F., 1998. Seasonal dynamics of colored dissolved material in the Sargasso Sea. Deep-Sea Res. 45, 931-957.

Pegau, W.S., Gray, D., Zaneveld, J.R.V., 1997. Absorption and attenuation of visible and near-infrared light in water: dependence on temperature and salinity. Appl. Opt. 36, 6035-6046.

Roesler, C.S., Perry, M.J., 1995. In situ phytoplankton absorption, fluorescence emission, and particulate backscattering spectra determined from reflectance. J. Geophys. Res. 100, $13279-13294$

Roesler, C.S., Perry, M.J., Carder, K.L., 1989. Modeling in situ phytoplankton absorption from total absorption spectra. Limnol. Oceanogr. 34, 1512-1525.

Schwarz, J.N., Kowalczuk, P., Cota, G.F., Mitchell, B.G., Kahru, M., Chavez, F.P., Cunningham, A., McKee, D., Gege, P., Kishino, M., Phinney, D.A., Raine, R., 2002. Two models for absorption by coloured dissolved organic matter (CDOM). Oceanologia 44 (2), 209-241.

Shifrin, K.S., 1988. Physical Optics of Ocean Water American Institute of Physics, College Park, MD. 285 pp.

Sipelgas, L., Arst, H., Erm, A., 2000. Estimation of optical properties of yellow substance in Estonian and Finnish lakes. Proc. Ocean Optics XV, Monaco, 16-20 October. Office of Naval Research, USA CD-ROM.

Stedmon, C.A., Markager, S., 2001. The optics of chromophoric dissolved organic matter (CDOM) in the Greenland Sea: an algorithm for differentiation between marine and terrestrially derived organic matter. Limnol. Oceanogr. 46, 2087-2093.

Stedmon, C.A., Markager, S., Kaas, H., 2000. Optical properties and signatures of chromophoric dissolved organic matter $(\mathrm{CDOM})$ in Danish coastal waters. Estuar. Coast. Shelf Sci. 51, 267-278.

Thurman, E.M., 1985. Organic Geochemistry of Natural Waters. Martinus Nijhoff/Dr. Junk Publishers, Boston.

Twardowski, M.S., Donaghay, P.L., 2001. Separating in situ and terrestrial sources of absorption by dissolved materials in coastal waters. J. Geophys. Res. 106 (C2), 2545-2560.

Twardowski, M.S., Donaghay, P.L., 2002. Photobleaching of aquatic dissolved materials: absorption removal, spectral alteration, and their interrelationship. J. Geophys. Res. 107 (C8), $6.1-6.12$.

Twardowski, M.S., Sullivan, J.M., Donaghay, P.L., Zaneveld, J.R.V., 1999. Microscale quantification of the absorption by dissolved and particulate material in coastal waters with an ac9. J. Atmos. Ocean. Technol. 16, 691-707.

Vodacek, A., Blough, N.V., DeGrandpre, M.D., Peltzer, E.T., Nelson, R.K., 1997. Seasonal variation of CDOM and DOC in the Middle Atlantic Bight: terrestrial inputs and photooxidation. Limnol. Oceanogr. 42, 674-686.

Whitehead, R.F., et al., 2002. Interactions of ultraviolet-B radiation, mixing, and biological activity on photobleaching of natural chromophoric dissolved organic matter: a mesocosm study. Limnol. Oceanogr. 45, 278-291.

Wrigley, T.J., Chambers, J.M., McComb, A.J., 1988. Nutrient and gilvin levels in waters of coastal-plain wetlands in an agricultural area of western Australia. Aust. J. Mar. Freshw. Res. 39, 685-694.

Zaneveld, J.R.V., Kitchen, J.C., Moore, C.M., 1994. The scattering error correction of reflecting-tube absorption meters. Ocean Optics XII. Proc. SPIE, vol. 2258, pp. 44-55.

Zepp, R.G., Schlotzhauer, P.F., 1981. Comparison of photochemical behavior of various humic substances in water: 3. Spectroscopic properties of humic substances. Chemosphere 10, 479-486. 